Florida International University FIU Digital Commons

\title{
Exoneration or Observation? Examining a Novel Difference Between Liars and Truth Tellers
}

Peter F. Molinaro

Florida International University, pmoli007@fiu.edu

DOI: $10.25148 /$ etd.FI15032161

Follow this and additional works at: https://digitalcommons.fiu.edu/etd

Part of the Cognitive Psychology Commons, and the Forensic Science and Technology Commons

\section{Recommended Citation}

Molinaro, Peter F., "Exoneration or Observation? Examining a Novel Difference Between Liars and Truth Tellers" (2015). FIU Electronic Theses and Dissertations. 1833.

https://digitalcommons.fiu.edu/etd/1833 


\section{FLORIDA INTERNATIONAL UNIVERSITY}

Miami, Florida

\section{EXONERATION OR OBSERVATION? EXAMINING A NOVEL DIFFERENCE BETWEEN LIARS AND TRUTH TELLERS.}

A dissertation submitted in partial fulfillment of the requirements for the degree of

DOCTOR OF PHILOSOPHY

in

PSYCHOLOGY

by

Peter F. Molinaro

2015 
To: Dean Michael R. Heithaus

College of Arts and Sciences

This dissertation, written by Peter F. Molinaro, and entitled Exoneration or Observation? Examining a Novel Difference Between Liars and Truth Tellers, having been approved in respect to style and intellectual content, is referred to you for judgment.

We have read this dissertation and recommend that it be approved.

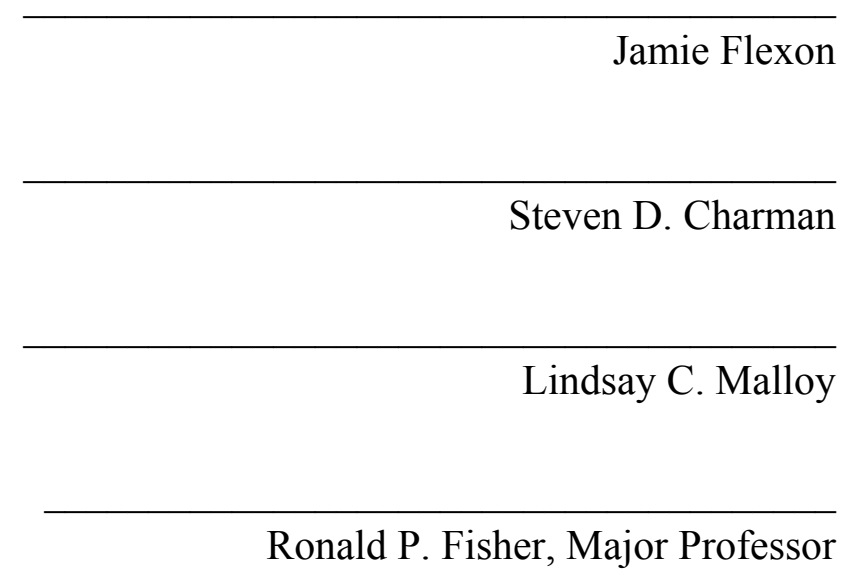

Date of Defense: March 26, 2015

The dissertation of Peter F. Molinaro is approved.

$\begin{array}{r}\hline \begin{array}{r}\text { Dean Michael R. Heithaus } \\ \text { College of Arts and Sciences }\end{array} \\ \hline \begin{array}{r}\text { Dean Lakshmi N. Reddi } \\ \text { University Graduate School }\end{array}\end{array}$

Florida International University, 2015 
(C) Copyright 2015 by Peter F. Molinaro

All rights reserved. 


\section{DEDICATION}

To my family, both here and in Oz, for their love and keeping me sane (sort of) throughout the writing of this work 


\section{ACKNOWLEDGMENTS}

This work would not have been possible without the tremendous support of my major professor, Ron Fisher. His guidance, mentorship and patience throughout every step of the process was invaluable and essential to the successful completion of this dissertation as well the overall success of my graduate career. I would also like to thank the members of my dissertation committee, Steve Charman, Lindsay Malloy, and Jamie Flexon, for their critical feedback and support throughout the course of this project. You have all inspired me to work on a variety of theoretical and applied projects, and I hope I can live up to the example you have all set for me.

I also wish to profusely thank my research assistants who worked with me on this project. In particular I would like to thank the truly amazing efforts of those research assistants who worked with me on phase 3 of this project, endured months of training, and even more months of data collection: Paula Suarez, Danielle Merritt, Jorge Perez, and Chris Thompson. I cannot overstate how grateful I am to have worked with you all on this dissertation. You were all amazing to work with and without you this research would not have been possible.

Finally this work would not have been possible without the love and support of my family and friends. While many of you were not in Miami for the bulk of this project, your support was essential to my successful completion of it. 


\section{ABSTRACT OF THE DISSERTATION \\ EXONERATION OR OBSERVATION? EXAMINING A NOVEL DIFFERENCE BETWEEN LIARS AND TRUTH TELLERS.}

by

Peter F. Molinaro

Florida International University, 2015

Miami, Florida

Professor Ronald P. Fisher, Major Professor

Individual cues to deception are subtle and often missed by lay people and law enforcement alike. Linguistic statement analysis remains a potentially useful way of overcoming individual diagnostic limitations (e.g. Criteria based Content Analysis; Steller \& Köhnken, 1989; Reality monitoring; Johnson \& Raye, 1981; Scientific Content Analysis; Sapir, 1996). Unfortunately many of these procedures are time-consuming, require in-depth training, as well as lack empirical support and/or external validity. The current dissertation develops a novel approach to statement veracity analysis that is simple to learn, easy to administer, theoretically sound, and empirically validated.

Two strategies were proposed for detecting differences between liars' and truthtellers' statements. Liars were hypothesized to strategically write statements with the goal of self-exoneration. Liars' statements were predicted to contain more first person pronouns and fewer third person pronouns. Truth-tellers were hypothesized to be motivated toward being informative and thus produce statements with fewer first person 
pronouns and more third person pronouns. Three studies were conducted to test this hypothesis. The first study explored the verbal patterns of exoneration and informativeness focused statements. The second study used a traditional theft paradigm to examine these verbal patterns in guilty liars and innocent truth tellers. In the third study to better match the context of a criminal investigation a cheating paradigm was used in which spontaneous lying was induced and written statements were taken. Support for the first person pronoun hypothesis was found. Limited support was found for the third person pronoun hypothesis. Results, implications, and future directions for the current research are discussed. 


\section{TABLE OF CONTENTS}

CHAPTER

PAGE

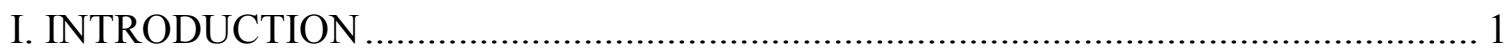

Pitfalls of current deception detection methods ......................................................... 1

Linguistic Statement Analysis - current approaches .................................................. 3

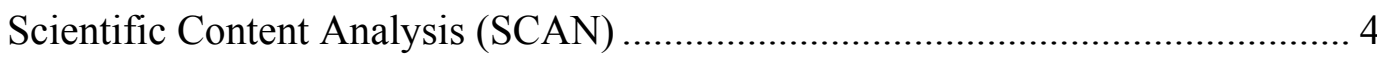

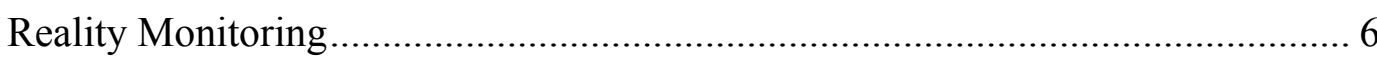

Criterion based content analysis (CBCA) ..................................................... 7

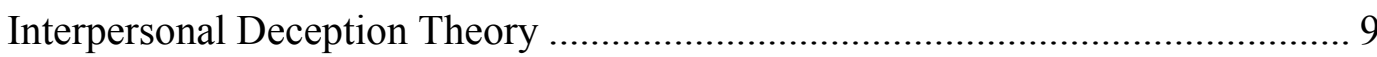

Linguistic Inquiry and Word Count (LIWC) ....................................................... 10

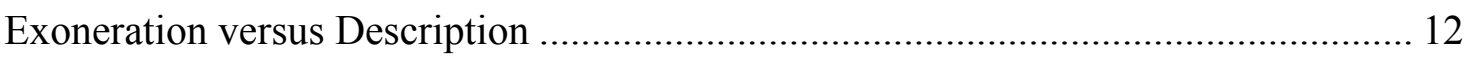

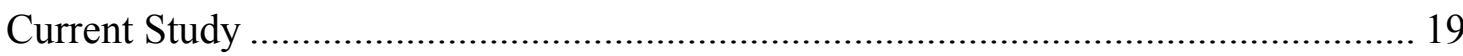

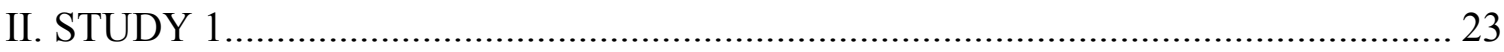

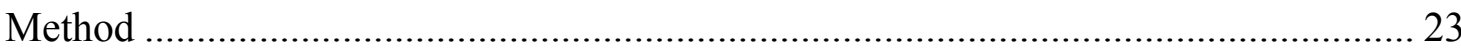

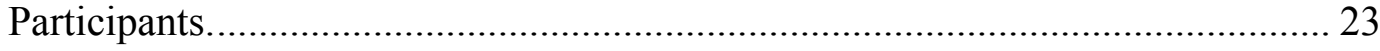

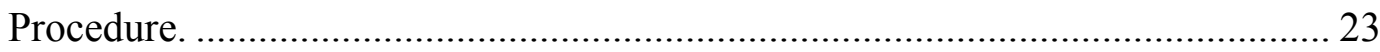

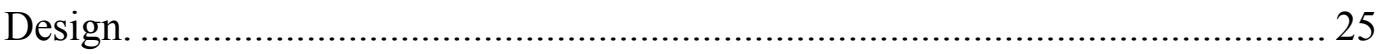

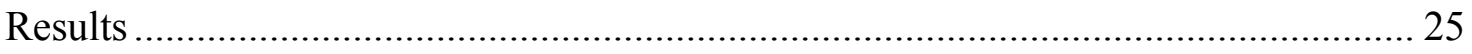

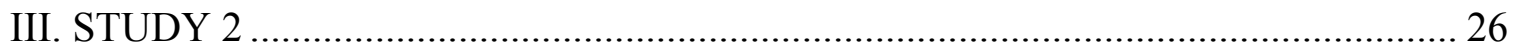

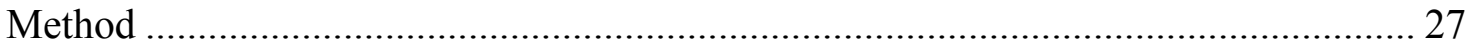

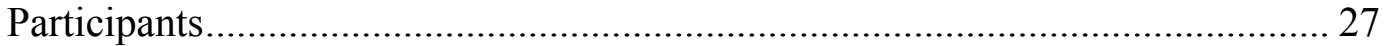

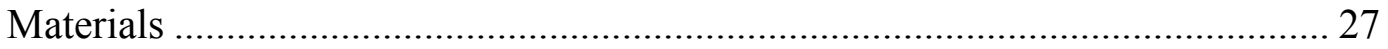

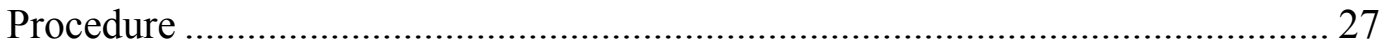

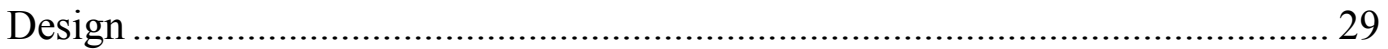

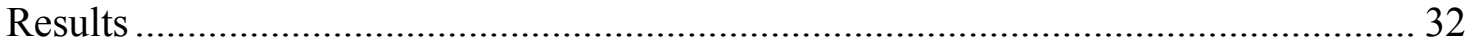




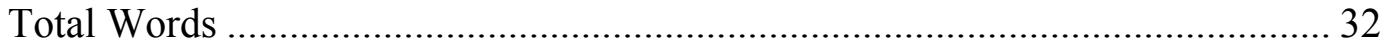

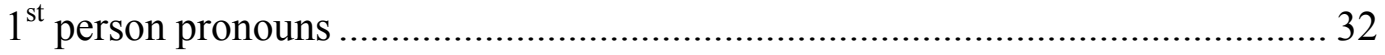

$3^{\text {rd }}$ person Pronouns................................................................................... 33

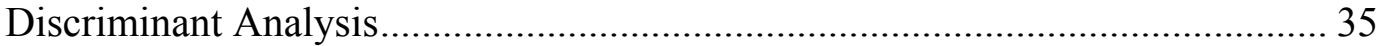

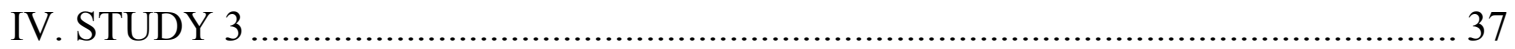

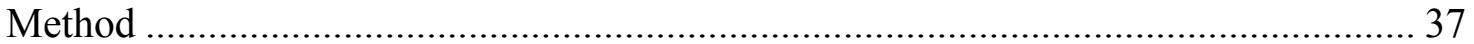

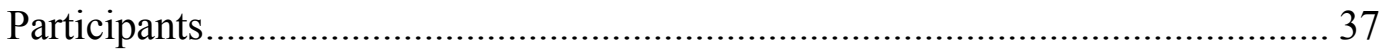

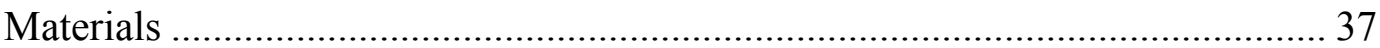

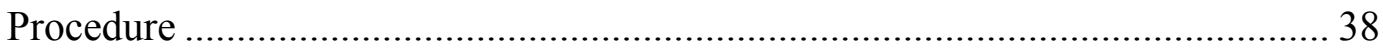

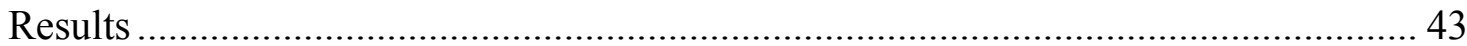

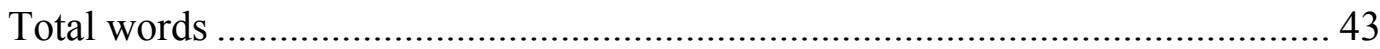

Absolute numbers of first \& third person pronouns ...................................... 43

Proportional frequency of first and third person pronouns ............................... 44

Proportional frequency of singular and plural pronouns ................................. 44

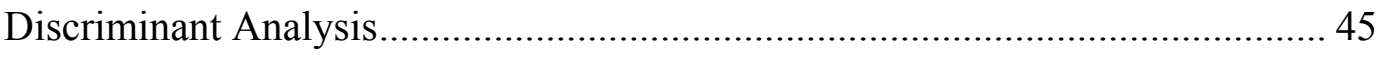

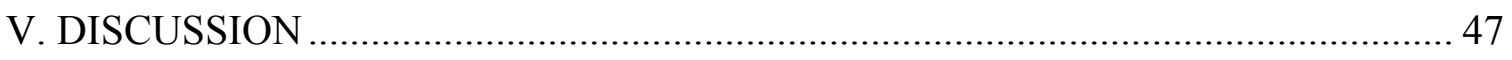

Implications for Researchers and Practitioners ..................................................... 50

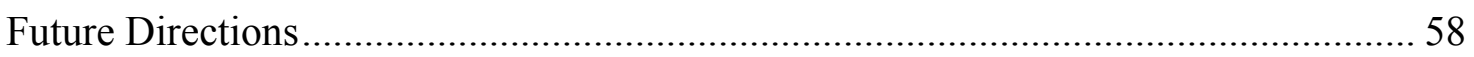

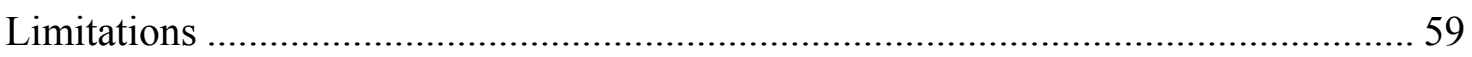

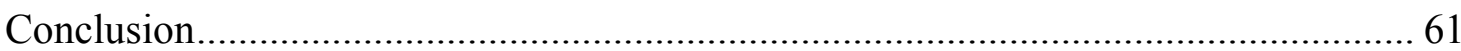

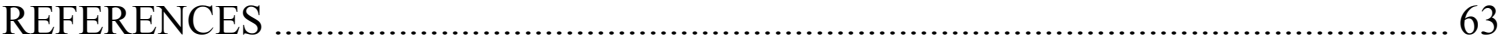

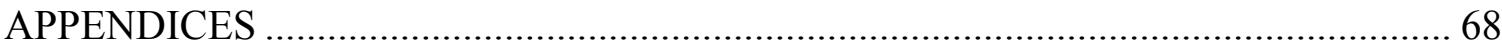

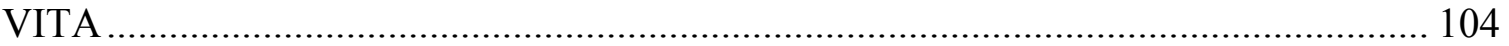




\section{LIST OF TABLES}

TABLE

PAGE

1. Pronoun Operationalization and Classification .................................................18

2. Absolute number of words in statements by lying condition in Study 2 ...............34

3. Relative proportion of pronouns in statements by lying condition in Study 2 ......35

4. Absolute number of words in statements by lying condition in Study 3 ..............44

5. Relative proportion of pronouns in statements by lying condition in Study $3 \ldots . . .45$ 


\section{ABBREVIATIONS AND ACRONYMS}

$\begin{array}{ll}\text { BAI } & \text { Behavioral Analysis Interview } \\ \text { CBCA } & \text { Criterion Based Content Analysis } \\ \text { CI } & \text { Cognitive Interview } \\ \text { IDT } & \text { Linguistic Inquiry and Word Count } \\ \text { LIWC } & \text { Not Significant } \\ \text { NS } & \text { Reality Monitoring } \\ \text { RM } & \\ \text { SCAN } & \text { Scientific Content Analysis } \\ \text { WAIS } & \text { Wechsler Adult Intelligence Scale }\end{array}$




\section{INTRODUCTION}

Linguistic analysis of suspect statements remains an important tool for deception detection. The overarching argument upon which all linguistic analysis techniques are derived is simply that liars' and truth tellers' statements are systematically different based on the basis of a quantifiable verbal difference. Several notable concerns call into question the utility of many current linguistic analysis techniques. First, many techniques currently in use (e.g. SCAN; Sapir, 2005) have not been supported empirically. Second, other techniques that have been validated empirically have been tested in a laboratory environment that may not be analogous to real world criminal investigations. The current dissertation will argue theoretically for and demonstrate empirically a novel approach to linguistic deception detection relying on a theorized difference in the goals of guilty liars and innocent truth tellers.

\section{Pitfalls of current deception detection methods}

The accurate detection of deception is paramount to the success of law enforcement and will remain so for the foreseeable future. Unfortunately, laboratory studies suggest that the diagnosticity of detecting deception is only slightly higher than chance levels (Aamodt \& Mitchell, 2004; Vrij, Edward, \& Bull, 2001). These relatively poor accuracy rates of detecting deception may be a consequence of an over-reliance on cues that are only tangentially related to deception (see Vrij, 2008 for review). DePaulo, Lindsay, Malone, Muhlenbruck, Charlton, \& Cooper's (2003) meta-analysis found that across a wide range of studies deception cues are subtle and rarely discernible. Bond and DePaulo (2008) examined individual differences in detecting deception and found that 
across 247 studies individual accuracy rates varied by less than $1 \%$ with an average accuracy of $54 \%$. That is to say human deception detectors were universally and consistently poor at actually detecting deception. Bond and DePaulo postulate that their observed poor detection rates may be the result of evaluators' deception judgments being based on visible signs of arousal. Poor deception detection ability is problematic for investigators relying on arousal-based cues in that these cues may not be diagnostic of deception. Nevertheless, many investigators continue to rely on techniques such as the Behavioral Analysis Interview (BAI), an arousal-based approach, when making judgments about the veracity of suspects' statements (Inbau, Reid, Buckley, \& Jayne, 2013; Bull, 2004).

Currently, the BAI is among the most commonly used and taught means of preinterrogation interview to detect guilty liars in the United States (Inbau et al., 2013). Inbau and colleagues actively recommend probing suspects for signs of arousal that will separate aroused liars from allegedly non-aroused truth-tellers. Probing for arousal, in turn, should lead investigators to "easily" discern cues identifying a liar from a truth teller. Arousal-based approaches stem from a commonly made, but mistaken, assumption that anxiety in an investigative interview is attributable only to deception (Vrij, 2008). Indeed, research into the BAI categorically contradicts assertions that it is able to accurately detect deception. Kassin and Fong (1999) examined the ability of the BAI to detect guilty from innocent suspects. The BAI was found not to improve the diagnostic ability of investigators. It did, however, increase investigators' overconfidence in their assessment of suspect veracity. Vrij, Mann, and Fisher (2006) examined the components 
of the BAI individually for deception detection ability and similarly failed to find any diagnostic support for the BAI's methodology. The flaws of the BAI and other arousal/behavioral methods of deception detection have necessitated the development of more empirically valid techniques that circumvent their diagnostic limitations.

\section{Linguistic Statement Analysis - current approaches}

One important way in which investigators and researchers have attempted to overcome flawed individual deception detection is through the verbal analysis of written statements. Analyzing the veracity of written statements offers a key advantage over arousal-based methods of deception detection. Vrij (2004) argues that verbal statement analysis strips away supposed "deception cues" from analysis (e.g., grooming behaviors, nervous movements) which are overemphasized and incorrectly believed to be indicative of deception (Akehurst, Köhnken, Vrij, \& Bull, 1996; Vrij \& Taylor, 2003). The absence of these "red-herring" cues allows investigators to hone in on verbal differences, which potentially offer a more clear-cut means of discriminating true from false statements. Studies have shown that when investigators rely on more behavioral cues, their deception detection accuracy rests at around 55\% (Vrij \& Mann, 2003; Granhag \& Vrij, 2005). In contrast, when investigators employ verbal statement analysis their deception detection accuracy rates average at around $72 \%$ (Vrij, 2005). Verbal statement analysis circumvents potential distractions present in more traditional arousal-based methods and offers a much needed and useful investigative tool in deception detection. 
Five key methods of linguistic statement analysis have emerged and are currently in use in a variety of investigative and experimental contexts. First, Scientific Content Analysis (SCAN), developed by a former polygrapher, is a method of verbal credibility assessment (Sapir, 2005). Second, Reality Monitoring (RM) is a more cognitive approach to deception detection based on memorial differences between constructed memories (lies) and actual memories (truths) (Johnson \& Raye, 1981). Third, Criterion Based Content Analysis (CBCA), commonly used for statement credibility assessment in Europe, is similarly developed from the strategic and cognitive differences in liars and truth tellers (Steller \& Köhnken, 1989). Fourth, Interpersonal deception theory (IDT) examines verbal differences within the context of interpersonal communication, which is based heavily on key differences in the strategic goals of liars and truth tellers (Buller, Burgoon, Buslig, \& Roiger, 1994; Buller \& Burgoon, 1996). Fifth, Linguistic Inquiry and Word Count (LIWC), developed by Newman, Pennebaker, Berry, and Richards, (2003) is a computer-based method of statement analysis that stems from the structural language differences between liars and truth tellers. Together, these statement analysis techniques provide a theoretical basis for the current proposal.

\section{Scientific Content Analysis (SCAN)}

Scientific Content Analysis (SCAN) is a frequently used method of verbal statement analysis in many countries including the US, UK, Canada, and Australia (see http://www.lsiscan.com/id29.htm). Scientific Content Analysis (SCAN) is predicated on the assumption that liars' statements will differ phenomenologically from those of truth tellers (Sapir, 2005). Scientific Content Analysis (SCAN) begins by directing 
witnesses/suspects to write down everything that they remember occurring during a specified length of time. Critically, this written account should not be influenced by an investigator, and SCAN specifies that the investigator should neither interfere with nor be present during the production of this "pure" version of events. Unlike many other standardized methods of statement analysis SCAN does not have a formalized set of criteria, instead framing itself as a set of tools or guidelines for investigators. Several notable inclusions within these guidelines include whether or not specific pronouns are used or avoided. For instance, Sapir argues that because liars are fabricating their accounts they are less likely to use more "concrete" first person pronouns. For example, a liar might say "You could see that the criminal had a gun," whereas a truth teller would be more likely to state "I saw that the criminal had the gun". Other SCAN indicators of deception include a reported lack of memory, missing links between various parts of statements, the absence of spontaneous corrections, and lack of past tense verbs. A common thread among these various indicators is that because liars' statements are constructed (either wholly or in part) they will be structurally different from the memorybased statements of truth tellers.

There has been a paucity of research to validate SCAN. However, two notable studies to date have found no evidence for its diagnostic ability to detect deception. Porter and Yuille (1996) specifically tested 3 of SCAN's general guidelines: 1) avoiding use of first person singular pronouns, 2) missing information, and 3) inconsistencies in the overall structure of the statement. They found no significant differences for each of these three criteria across deceptive and truthful statements. More recently, Nahari, Vrij 
and Fisher (2012) failed to find any evidence for SCAN's ability to discriminate between deceptive and true statements. Although experimental studies have failed to find support for SCAN, a field study conducted by Smith (2001) offered some evidence in support of SCAN. Smith demonstrated that investigators using SCAN were able to identify about $80 \%$ of truthful statements and $65 \%$ of false statements. However, similar results were found for detectives not trained in SCAN who used their past experiences as investigators to assess statements. These data call into question whether SCAN or investigator experience mediated diagnostic ability. Additionally, Smith found that the actual SCAN criteria used by the investigators revealed low levels of consistency. While SCAN remains a widely used statement analysis technique, its actual diagnostic usefulness remains tenuous at best.

\section{Reality Monitoring}

Reality monitoring is another approach to the analysis of verbal statements. It was originally developed as a means to examine differences in the quality of eventderived versus internally-derived (made up) memories. Johnson and Raye (1981) proposed that there are two distinct types of memories: internal and external memories. Internal memories refer to those memories within the cognitive environment. Specifically, they refer to memories about internal cognitive experiences such as logic and reasoning, retrieval, mental imagery, and metacognition. Conversely, external memories refer to actual experiences that an individual may have encountered through the senses (e.g., smell, taste, and touch). Reality monitoring posits that true memories will contain sensory information relevant to the particular memory being encoded. 
According to reality monitoring theorists, constructed or imagined events will contain less externally derived information compared to memories that are derived externally. Instead, these internally derived false memories are theorized to contain more information about internal mental processes.

Sporer (1997) reviewed a series of studies testing RM and found that truthful statements were more likely to contain detailed spatial and temporal information than internally-derived memories, which is consistent with the predictions of RM. However, only a single study has found evidence for deceptive statements containing more information about internal cognitive operations than truthful statements (HernandezFernaud \& Alonso-Quecuty, 1997).

Notably, Porter and Yuille (1996) found that, in an interrogative context, no differences were found between truthful and deceptive statements on any of the expected RM criteria. RM has also been shown to be ineffective in populations (e.g., children, psychotics) where differentiating between reality and fantasy is not clearly defined (Lindsay \& Johnson, 1987; Johnson, 1988). Given these mixed findings, RM's utility as a means of statement analysis is difficult to classify. Reality Monitoring (RM) may be best as a general guideline for investigators and less as an absolute means of detecting truthful and deceptive statements.

Criterion based content analysis (CBCA)

Criterion based content analysis (CBCA) was developed by Steller and Köhnken (1989) as a means of statement analysis and is based on the earlier Undeutsch hypothesis 
(Undeutch, 1967). The Undetsch hypothesis states that because liars are imagining or creating their statements, whereas truth tellers are simply retrieving from memory, their statements will differ in terms of both content and quality. The original derivation of CBCA contained a formalized set of 19 criteria divided into 4 key areas which target the theorized differences in statement content and quality. These areas include: 1) general characteristics, 2) specific content, 3) motivationally derived content and, 4) offensespecific content. Criterion Based Content Analysis (CBCA) requires highly trained evaluators to examine statements in each of these areas. If a criterion is judged to be present it is regarded as an indication that a statement may be truthful. Unlike many other forms of verbal statement analysis, the focus of $\mathrm{CBCA}$ is on detecting true statements (contrary to detecting lies). Furthermore, CBCA was developed and standardized to evaluate the statements of child witness/suspects. However, it has also been adapted for adults (Landry \& Brigham, 1992). Although research has demonstrated the usefulness of CBCA with its originally intended population (Vrij, 2005), mixed findings and potential issues with its focus on truthfulness have yielded problems (e.g., Blandon-Gitlin, Pezdek, Rogers, \& Brodie, 2005; Vrij, Akehurst, Soukara, \& Bull, 2002).

Vrij $(2008 ; 2005)$ examined the diagnosticity of CBCA across a variety of studies concluding that it could accurately determine truthful from deceptive statements approximately $70 \%$ of the time. Two potential drawbacks to the more widely accepted use of $\mathrm{CBCA}$ are the level of training required for interviewers, as well as the time necessary to analyze individual statements on the many criteria (Akehurst et al., 2004). Akehurst and colleagues found that although training in the use of CBCA improved a 
layperson's capability to detect deception, it reduced the ability of law enforcement to detect deception. The authors posit that the reduction of deception detection ability may be due to the complexity of CBCA, as well as the limited amount of time law enforcement devoted to training. There are several other notable limitations of CBCA that preclude it from more widespread use. First, as CBCA was developed originally for children, some of the diagnostic criteria do not work for adults (Landry \& Brigham, 1992). Additionally, since CBCA's criteria focus on detecting truthful statements (not deception), lies of omission or equivocation that may draw on truthful memories could mislead investigators into classifying the entirety of those statements as truthful (Porter \& Yuille, 1996; Ruby \& Brigham, 1997). A final potential limitation of CBCA is the intensive knowledge and familiarity evaluators are required to possess when examining statements. An investigator's extensive prior knowledge, though required, could unduly influence investigators, particularly if a statement is ambiguous. Overall, CBCA is highly effective in the contexts it was designed for, though potentially less effective the more it strays from its originally intended population and purpose.

\section{Interpersonal Deception Theory}

Interpersonal Deception Theory (IDT) attempts to classify the deceptiveness of a statement within a communicative and interpersonal context. IDT proposes six general strategies employed by liars that result in linguistic differences from the statements of truth tellers (Buller \& Burgoon, 1994; Buller et al, 1994; Burgoon et al, 1996). First, liars may manipulate the quality of their statements. Instead of telling an outright lie, liars may employ half-truths or equivocations through a careful use of adjectives and 
adverbs that qualify the meaning of a particular statement. Second, IDT predicts that liars will be more reticent in their verbal reporting than truth tellers, to avoid revealing incriminating information. Liars are thus expected to produce statements containing fewer words than truth tellers. Third, liars are expected to use vagueness or ambiguity in their word choices instead of opting for more absolute words/phrasing (e.g., "Some guests at the party may have seen a gun." instead of "Everyone who attended at the party saw the gun."). Fourth, according to IDT, liars should provide more irrelevant or indirect information about the event in question compared to truth tellers. Fifth, IDT postulates that liars should make use of verbal tactics that are aimed at avoiding discrediting information and acknowledging the limits of their statements (e.g. admitting to a fuzzy memory at the onset). Finally, IDT makes a similar prediction to SCAN, that liars will use fewer self-referencing statements and first person pronouns compared to truth tellers.

\section{Linguistic Inquiry and Word Count (LIWC)}

Newman, Pennebaker, Berry, and Richards (2003) developed a technique known as Linguistic Inquiry and Word Count (LIWC), which approaches statement analysis from a more linguistic perspective. Linguistic Inquiry and Word Count (LIWC) is derived from Pennebaker, Mehl, and Niederhoffer's (2003) earlier method of linguistic statement analysis which was not specifically tailored for predicting deceptive responses. Unlike many of the other approaches discussed, LIWC focuses on words that are not directly associated with the content of statements (e.g., articles, pronouns and prepositions) when analyzing the veracity of a statement. Thus, LIWC is focused on examining how individuals say something more so than what it is they're saying. 
Linguistic Inquiry and Word Count (LIWC)suggests that liars will produce statements that are 1) linguistically less complex 2) less self-based, and 3) more negative than the statements produced by truth tellers. Critically, Newman and colleagues found support for LIWC's diagnostic ability as a function of the differing grammar and non-content word usage by liars and truth tellers.

Although LIWC's ability to detect deception was robust and highly diagnostic of deception, several notable problems preclude Newman et al.'s (2003) technique from being generally adopted. First, Newman et al.'s analysis requires the use of an advanced unique software package to identify statements as self-referential. The software requirement is potentially problematic, as it requires that law enforcement have available the particular LIWC software package, in addition to a high level of technical knowledge and expertise to interpret the complex program output. Second, and perhaps more important, Newman et al.'s paradigm tested lies about a social attitude (e.g. abortion). Deceptive statements were centered on taking a perspective contrary to one's personal beliefs, and not lying to conceal a wrong-doing. As Newman and colleagues explain, liars are driven to distance themselves verbally from their lies as these lies go against the grain of their personal beliefs. Self-distancing was observed through a decreased use of first person pronouns and self-referential statements. Unfortunately, lies most commonly proffered in legal contexts are not lies about beliefs in social ideologies, but rather lies to deflect suspicion from oneself about a suspected wrong-doing, and thus avoid subsequent repercussions. Lies created to exonerate are categorically different from the type of lies 
studied by Newman and colleagues, and as such, may not be governed by the same theorized strategic principles.

Each of the currently available methods of verbal statement analysis shares an integral common theme. Liars and truth tellers use different strategies when producing statements and these strategic differences can lead to verbal differences, either in the content of messages or the way the messages themselves are structured grammatically. The reviewed statement analysis methods also share a relatively high level of complexity, requiring considerable investment and training on the part of the investigator. Another essential common thread throughout many of the reviewed statement analysis methods is that liars will seek to personally distance themselves from their lies. This is expected to be manifested by a lack of first person pronoun usage or an avoidance of self-referential statements. Although many of the reviewed techniques are highly diagnostic within a given context, mixed findings and theoretical problems limit their net utility and diagnosticity. The theoretical issues are particularly problematic regarding the hypothesized differences in self-reference between liars and truth tellers.

\section{Exoneration versus Description}

The notion that liars may wish to personally distance themselves from their lies makes rational sense, however, empirical support for this hypothesis is limited. Consider the results of Porter and Yuille (1996) and Nahari et al. (2012) on SCAN's diagnostic

criteria. No evidence was found to support SCAN's premise that liars used fewer first 
person pronouns compared to truth tellers. Similarly, Buller and colleges (1994) predicted that liars would use fewer first person pronouns compared to truth tellers. Contrary to their expectations, they reported finding exactly the opposite (i.e. liars used proportionately more first person pronouns than truth tellers). Buller et al. fail to account for this finding within the context of IDT. Although Newman and colleagues found evidence to support their hypothesis about liars' avoidance of self-reference, the overriding socio-ideological context of those deceptive statements may have affected their use of first and third person pronouns. As previously discussed, lies that were produced contextually from an ideological viewpoint that an individual does not agree with may result in substantially different statements than lies in a typical criminal investigative context. Indeed, as argued by Buller et al. (1994) as well as by Steller \& Köhnken (1989), it is context that may have a critical impact on shaping the strategies of both truth tellers and liars.

Narrative Manipulation is listed among the strategies employed by liars in IDT (Buller et al., 1994). Deceptive individuals have been shown in a variety of settings to avoid producing incriminating details in their reporting (DePaulo et al., 2003). Concurrently, Buller et al. (1994) argue that liars are still bound by the same pressures of interpersonal communication to produce a response. If the relative costs of producing a truthful response are too high, liars are left with two potential options. First, they may create a detailed narrative that is to some extent fabricated. However, there are notable risks associated with this sort of confabulation, namely, that their story may be refuted later if further evidence comes to light. If liars did create a fictitious narrative with which 
to exonerate themselves, it would, however, resemble Johnson and Raye's (1981) concept of an internally derived memory. If a deceptive statement contains many internally derived memories, then it is reasonable to expect that the focus of that statement will be on the deceiver to a greater extent than it would be were the narrative derived from an external, observable event memory. Second, liars can mislead and misdirect the focus of the narrative from describing the wrong-doing to describing something innocuous which exonerates them from involvement and suspicion. For instance, if a guilty suspect was questioned by police about his/her potential involvement in a murder at a party, rather than describe his/her witnessing of the party and details associated with the murder, he/she might instead focus his/her narratives more narrowly on his/her own actions. Such a statement would satisfy the suspect's interpersonal obligation to provide information to investigators as well as his/her two-fold strategic goals of avoiding revealing incriminating information and providing potentially accurate exonerating memories. Whether a liar takes on one or some combination of both approaches in his/her narratives, a guilty liar who is focused on a strategic goal of exoneration will be faced with an inevitable and pervasive emphasis on him/herself and "his/her" actions over a focus on the situation. For example, a guilty liar suspected of involvement in a bar fight might say:

"I was just sitting at the bar minding my own business. Nobody was bothering me and I was keeping to myself. I had my drink and I was watching the ballgame. I wasn't anywhere near the victim so I'm pretty surprised that I'm being questioned since I wasn't there and I didn't have anything to do with the fight. 
In spite of the findings of Newman and colleagues (2003), liars will need to selfreference and provide relevant first person pronouns in support of these statements in order to successfully exonerate themselves, particularly when unable to provide truthful exonerating information. Indeed, this may also account for the increased prevalence of self-references found by Buller and colleagues (1994). Liars should then produce substantially more self-referential statements and necessarily use more first person pronouns.

Truth tellers and liars should share the same strategic goals. For innocent truth tellers, the communicative and personal costs of providing deceptive information should be necessarily outweighed by the benefits of providing honest, accurate information. According to the Self-Presentational Perspective (DePaulo et al., 2003) truth tellers, similar to liars, should be strategically motivated to prove their innocence. However, truth tellers may perceive an additional benefit in providing accurate information (i.e. aiding the investigator). Truth tellers may value this cooperation on the basis of two potential motivations: 1) aiding the investigators who are perceived to be aiding society is considered the social norm and subscribing to this norm may be considered the most appropriate behavior for a member of a particular social community; 2) out of selfinterest stemming from a desire to see the actual perpetrator come to justice (Tyler \& Fagan, 2008). Consider also Buller et al.'s (1994) argument about the dynamics of interpersonal interaction. It is clear that liars will be motivated to satisfy the communicative goal of the individual who is questioning them and thus engage in conversation by providing (deceptive) information. It stands to reason that truth tellers 
should also be motivated by this same communicative goal to converse and to provide information. Truth tellers also have a distinct advantage over liars. Providing accurate and specific information within the communication context will not pose a threat to the truth teller's goal of maintaining innocence. In fact, this information may aid in both satisfying the questioner as well as establishing the truth teller's own innocence. Kassin et al. (2010) make the argument that the phenomenology of innocence is such that innocent individuals find their innocence apparent, and do not feel the same communicative reticence displayed by a guilty suspect (Kassin \& Norwick, 2004). Indeed, innocent individuals seem very willing to provide information to investigators. The phenomenology of innocence supports the notion that innocence could drive truth tellers to adopt a strategy of informativeness aimed at aiding themselves and potentially the investigation. If innocent truth tellers are indeed adopting the role of a witness then their statements should contain key differences from the more internally derived (and self-referenced) statements of liars.

Reality Monitoring (RM) (Johnson \& Raye, 1984) makes a very important prediction about the focus of truthful and deceptive statements. Truthful statements are theorized to be based on observable (external) memories. External memories are theorized to contain considerable descriptive information and highly specific sensory details about an observed event. In contrast, RM predicts that deceptive statements will be based on the internal cognitive state of the individual from which they are derived. If truthful statements do contain more external memories then it is reasonable to expect that the perspective of those memories should be in the third person. Similar to a witness, an 
innocent truth teller would be an observer, describing events as they took place. The organization of that event memory as an observed phenomenon would necessitate the use of the third person. The truth teller in producing statements about the external observable environment would potentially describe these events not from the self-focused perspective of the liar but from the third person as a rememberer and as a witness. An innocent truth teller might describe the previous hypothetical bar fight to investigators in the following way:

"It was a little after 10 o'clock when the scuffle started. The ballgame was on and it was about at the start of the $9^{\text {th }}$ inning when they started fighting. I couldn't see much but it seemed to be started by one guy who maybe had a bit too much to drink and it seemed like maybe he was upset that his team was losing. He was medium build, maybe early forties, and he had greying brown hair."

The truth teller in this case describes the event as an external observer since that is essentially how he/she would have encoded the memory as predicted by RM. This is also amenable to the predictions made by $\mathrm{CBCA}$ in that statements made by truth tellers should be highly descriptive (Steller \& Köhnken, 1989). For the truth teller, selfreference is required only to place him/herself within the context of an observed event. In contrast, if a liar is creating statements that are derived internally, then those memories should be self-focused as they originated from within the liar with the intention of exonerating the liar. These essential grammatical differences in the use of first and third person pronouns may serve to simply and accurately classify the statements made by liars 
and by truth tellers (refer to Table 1, for first and third person pronoun classification and operationalization).

Table 1

Pronoun Operationalization and Classification

\begin{tabular}{|c|c|c|c|c|}
\hline & \multicolumn{2}{|c|}{ First Person Pronouns } & \multicolumn{2}{|c|}{ Third Person Pronouns } \\
\hline & Singular & Plural & Singular & Plural \\
\hline Subject & I & we & he, she, it & they \\
\hline Object & me & us & him, her, it & them \\
\hline $\begin{array}{l}\text { Possessive } \\
\text { determiner }\end{array}$ & my & our & his, her, its & their \\
\hline $\begin{array}{l}\text { Possessive } \\
\text { Pronoun }\end{array}$ & mine & ours & his, hers & theirs \\
\hline Reflexive & myself & ourselves & $\begin{array}{l}\text { himself, } \\
\text { herself, itself }\end{array}$ & themselves \\
\hline
\end{tabular}

Another important finding relevant to the exoneration versus informativeness hypothesis is the notion that liars are less forthcoming in their verbal statements than truth tellers (See DePaulo et al., 2003 for review). This finding fits naturally with the current hypothesis in several ways. First, if liars are motivated to achieve selfexoneration, speaking too much could jeopardize that goal. A verbose lie might be difficult to remember, particularly given what is known about the increased cognitive demands of lying in general (e.g. Vrij et al., 2008). Additionally, too much information, even untruths, could reveal a lie and stoke investigator suspicion (Hartwig, Granhag, 
Strömwall, \& Kronkvist, 2006). Second, if truth tellers are motivated to be informative and helpful to investigators (as cooperative eyewitnesses) then they should be motivated naturally to be forthcoming with the information they possess. Additional truthful information would serve both to aid investigators in finding the actual culprit as well as establish innocence if needed. These differences in expected statement length may serve as an important ancillary hypothesis to the predicted self-referential differences in discriminating between the informative statements of truth tellers and the exonerative statements of liars. Longer statements for liars and shorter statements for truth tellers would replicate the findings of past deception studies and provide added support for the exoneration versus informativeness hypothesis.

\section{Current Study}

The current dissertation sought to examine both the previously found differences in liars' and truth tellers' statement lengths and the as-yet-unexamined, strategic difference between liars and truth tellers their differing use of first and third person pronouns. Verbal differences, produced by differing strategic goals of exoneration and informativeness, may serve to differentiate liars from truth tellers. I hypothesized that truth tellers should use their innocence and the information that they possess as an advantage, concurrently achieving both exoneration for themselves and aiding the investigator. I also predicted that truth tellers would use fewer first person pronouns than liars as truth-tellers' reporting strategy is motivated more toward providing information that is witnessed externally. Liars, in contrast, would be motivated to establish their innocence and not to aid investigators. Thus, any information provided by liars would be 
tailored to meet that goal. Liars' statements were predicted to be necessarily selfcentered and not primarily focused on describing a witnessed event. Additionally, if liars produced internally derived false memories to aid in their reporting then they should produce statements that are more self-referential. Liars' deceptive statements should summarily contain a higher proportion of first person pronouns compared to the statements made by truth tellers. The planned method of self-referential verbal content analysis would overcome many of the problems inherent in the previously reviewed methods of statement analysis including time and training costs, possessing a theoretical basis, and having clear external validity by better emulating the types of truthful and deceptive statements made by actual suspects. The current dissertation critically operationalizes self-reference by examining two key proportions: 1) The proportion of first person pronouns to overall words and 2) The proportion of third person pronouns to overall words.

The primary goal of the current dissertation was to validate a self-referential analytic method of verbal statement analysis that can be implemented easily by law enforcement. It must be initially established that truth tellers make use of both an exoneration-focused strategy as well as an informativeness strategy and that linked to both of these strategies are the hypothesized differences in the use of first- and third person pronouns. To examine the hypothesized strategic differences, innocent participants engaged in a perspective-taking exercise. Some participants took the perspective of a typical eyewitness, whereas others took the perspective of someone suspected of involvement in a mock crime. Study 1 established the exoneration versus 
informativeness premise by staging a mock crime in a class room. Participants were instructed to record their version of an observed crime either from the perspective of a witness or as someone suspected of involvement in the observed crime. I predicted that when taking the perspective of a suspect, participants would use fewer words, more first person pronouns, and fewer third person pronouns in their statements than those in the witness condition. Study 1 served to demonstrate that the predicted verbal-differences were present in the hypothesized word usage patterns. Studies 2 and 3 would apply this hypothesis to the relevant populations of guilty liars and innocent truth tellers.

Study 2 further developed the strategic differences hypothesis by examining verbal differences in guilty liars with innocent truth tellers. Liars were instructed to commit a crime and conceal their involvement. Both liars and truth tellers were asked to write statements aiding the research assistant to figure out what happened during the experiment. When given the same non-accusatory, information-focused instruction it was hypothesized that truth tellers would become more motivated to provide accurate information about their observations in the lab. Subsequently it was expected that truth tellers would use more third person pronouns and fewer first person pronouns in their statements. Liars should be far more defensive even when provided a non-accusatory instruction. I predicted that liars would maintain their strategic focus toward exoneration with very little or no motivation to aid in the investigation. Liars' statements were expected to contain proportionately more first person pronouns and fewer third person pronouns. 
Study 3 served as an essential ecologically valid replication of the first two studies. A major limitation of Study 2 is that liars were instructed explicitly to lie and to commit a crime. Study 3 addressed this limitation by implicitly directing individuals to lie by implicating them in a guilty action. Study 3 made use of a variation on the Russano cheating paradigm (Russano, Meissner, Narchet, \& Kassin, 2005). Liars were implicated in cheating by helping a confederate who is struggling on an experimental test question. Both liars and truth tellers were asked at the conclusion of the test phase to provide a written statement of what happened to aid in investigating a case of potential cheating. It was made salient to all participants that the consequences of cheating could lead to academic dishonesty charges. I hypothesized that Study 3 would replicate the results of Study 2 and also extend its applicability to actual suspects. Additionally, the differences between liars and truth tellers' statements were predicted to be greater since participants were faced with the possibility of more serious consequences (see for example: Vrij \& Mann, 2001; Mann, Vrij, \& Bull, 2004). Taken together, this research may yield a simple and easily implementable diagnostic approach to detecting deception. 


\section{STUDY 1}

\section{Method}

Participants.

Thirty-two participants for Study 1 were recruited from the author's undergraduate psychology class and awarded extra credit for participation. The sample was predominantly female $(62.4 \%)$. The sample included $77.6 \%$ of self-identified Hispanic participants, 11.3\% Caucasian (non-Hispanic), and 7.4\% African American. Mean age was 24.30 years $[S D=3.36]$.

\section{Procedure.}

After providing written consent, participants were told that they would engage in a memory exercise at some point in the class. A confederate arrived prior to the start of class and sat in the classroom posing as a student. After a brief introduction to the experiment and how research credit would be awarded for those participating, at roughly five minutes into the class, the confederate complained about his grade loudly in front of the class and demanded that he be provided with extra credit. His staged requests were summarily declined. After 10 minutes of lecturing an alarm on my phone went off which I, as the instructor, explained was an emergency call and excused myself from the classroom. One minute after I left the classroom the disgruntled student confederate got up from his seat went to the front of the classroom and put my laptop in his bag and ran out of the classroom. When I returned to the classroom, I explained to the class that they just witnessed a mock crime. Participants were then provided randomly with one of two 
sets of instructions written at the top of a lined sheet of paper. In the witness condition participants were given the following instruction:

"The FIU campus police will need to take your statement about what happened.

Please write out in as much detail as you can your statement of what occurred in the space below (use the back of this paper if needed)."

In the suspect condition participants were given the same instruction with the following addition: "The police currently suspect your involvement in the crime." Participants were given as much time as they required to write out their statements of events. The entire class finished after 20 minutes of writing. After all participants had finished with their written statements they were debriefed as to the true nature of the experiment.

Coding. An automated script was written by the author in the Python programming language to code all participant statements. The script identified and classified all pronouns based on the categories operationalized in table 1. The script produced an aggregated output for all statements which totalled the number of pronouns in each relevant category, as well as for the total number of words used. These categories included: total words, overall first person pronouns, first person singular pronouns, first person plural pronouns, overall third person pronouns, third person singular pronouns, and third person plural pronouns. 


\section{Design.}

Five dependent variables were examined across witness and suspect conditions. First, the overall number of words was examined. Next, both the absolute numbers of first person and third person pronouns were compared across conditions. Finally, the proportional numbers of first and third person pronouns were compared between groups. This number was calculated by taking the respective category of pronoun (i.e. first or third person) and dividing it by the overall number of words used in each participant's statement.

\section{Results}

Levine tests of homogeneity of variance were performed for all t-test. All tests failed to reach significance $(p s>.05)$. The total number of words used was not significantly different across suspects and witnesses $(p>.05)$ with a mean of 151.1 words for witnesses and 145.8 words suspects. Participants given the suspect instruction used significantly more first person pronouns in their statements $(M=6.53[5.77,7.29], S D=$ 2.95) than those given a witness instruction $(M=4.18[3.757,4.61], S D=1.78), t(30)=$ 2.78. $p=.01, d=1.02$. Significant differences were also observed for the raw number of third person pronouns with suspect participants using fewer third person pronouns $(M=$ $5.69[4.74,6.64], S D=3.61)$ compared to witness participants $(M=8.34[7.54,9.14], S D$ $=3.59) t(30)=2.13 \cdot p=.04, d=0.78$.

Proportional numbers of pronouns used were calculated by dividing the raw number of pronouns used by the total number of words used by that participant. A similar pattern of results to raw pronoun use was observed for proportional pronoun use. 
Suspect participants used proportionally more first person pronouns $(M=4.45 \%[3.86 \%$, $5.03 \%$ ], $S D=2.26 \%)$ than did witness participants $(M=2.86 \%[2.60 \%, 3.11 \%], S D=$ $1.05 \%) t(30)=2.50, p=.02, d=0.91$. For proportional use of third person pronouns suspects used fewer third person pronouns $(M=3.67 \%[3.21 \%, 4.12 \%], S D=1.76 \%)$ compared to witnesses $(M=5.01 \%[4.54 \%, 5.49 \%], S D=1.96 \%) t(30)=2.04, p=.05, d$ $=0.74$.

The Results of Study 1 while not perfectly matching on to my expectations, specifically in regard to statement length, did adequately provide initial evidence for the exoneration versus informativeness hypotheses. The lack of differences in statement length could easily be due to the fact that all participants in Study 1 were innocent truth tellers. Even when asked to take the perspective of a suspect, it is possible that participants were engaging in an informativeness strategy as providing additional information would aid in establishing their innocence. Study 2 would seek to build on the findings of Study 1 by applying them to the populations that are of essential interest to the current dissertation: guilty liars and innocent truth tellers. Given the findings of study 1, similar expectations were made for Study 2 in that liars performing a mock crime would self-reference and use fewer words compared to innocent truth telling participants. 


\section{STUDY 2}

\section{Method}

\section{Participants}

The participants in Study 2 were 30 undergraduate students participating for research credit. Their ages ranged from 18 to 34 years ( $M=21.43$ years). Participants selfreported their ethnicity in the following proportions: Hispanic (59.75\%), African American (22.9\%), and Caucasian (18.1\%). Most participants were female (66\%). Participants all self-reported as being highly proficient in English as their first language. Multilinguals who considered English a second (or third, etc.) language were screened out prior to signing up for the experiment via Florida International University's electronic participant system.

\section{Materials}

Study 2 Filler Tasks. Study 2 included a series of three filler tasks. The first filler task was taken from the picture completion sub-test of the Wechsler Adult Intelligence Scale third Edition (WAIS-III/Wechsler, 1997). The second filler task was a constructed series of word analogies (see Appendix ii). The final filler task was taken from the digit span working memory sub-test of the WAIS-III.

\section{Procedure.}

Participants were assigned randomly to a Lying or Truth telling condition. Sealed blank envelopes revealed their assigned role to the participants and provided relevant 
instructions while ensuring that the experimenter was unaware of the assignment. Liars were instructed to steal a set of answer keys to Psychology Department final exams kept on a flash drive labeled "final exam keys" on a table in the lab. Liars were told that the experimenter will step out of the lab for 10 minutes during the analogies test. The liars were given explicit instructions that they should steal the flash drive before the experimenter returns. Liars were also instructed not to reveal this action to the researcher under any circumstances, and to lie if directly questioned about their actions. Truth tellers were given a set of instructions stating that they will be taking several cognitive sub-tests and may be asked questions about their experience following completion of the tests. The length of both sets of instructions was 348 words.

Following random assignment and after instructions were read, participants were instructed that they would take some memory tests, assessing their working memory and spatial ability. First, participants were given the picture completion task where they had 2 minutes to put together an ambiguous puzzle into the shape of a butterfly. The butterfly task from the WAIS-III was designed to be challenging and was selected to ensure that the entire 2 minutes was used by virtually all participants. The experimenter then informed participants that they had 10 minutes to complete a written multiple-choice verbal analogies test. The experimenter stated that she needed to leave the lab during that time and make copies for her professor so the participants would be left alone in the room to complete the test. Participants were told that they could use the restroom, make phone calls etc., so long as they were finished with the analogies test and ready to begin the third test after the 10 minutes are up. During these 10 minutes liars were expected to 
steal the flash drive. After 10 minutes, the experimenter returned and administered the digit-span working memory sub-test. Participants were instructed to wait while the experimenter scored their results. After 3 minutes the experimenter returned asking them to come to their office. Participants were directed to sit at a computer where they were informed of the missing flash drive and given a non-accusatory information-gathering instruction to produce a statement about everything they can remember in the laboratory. Participants were then directed to type out their written statements and were subsequently debriefed. All liar statements were verified by author as being actually lies (i.e. deceptive statements about not stealing the flash drive when in fact they had). Similarly, all truth teller statements were verified as being honest accounts of their experience in the lab during the experiment.

Coding. The same automated script coded all participant statements, as described in Study 1, providing an aggregated data set for overall word and first and third person pronouns.

\section{Design.}

A simple between groups design was implemented to examine overall word and pronoun usage across liars and truth tellers. First- and third person pronouns were examined separately. Analysis included both the absolute number of pronouns and a relative/proportional number of pronouns. The proportional number was calculated by 
dividing the number of pronouns in a particular category (see table 1) over the total words used in a statement. 
Figure 1

Diagram of Study 2 Procedure

\begin{tabular}{|c|c|}
\hline \multicolumn{1}{|c|}{ Consent } \\
\hline Blind Instruction \\
\hline Test 1 (with RA) \\
\hline Test 2 (Alone) \\
\hline Test 3 (with RA) \\
$\begin{array}{c}\text { Guilty Liar - Theft occurs } \\
\text { while alone }\end{array}$ \\
\hline Innocent Truction \\
Control Instruction
\end{tabular}

Confrontation \& non-

Accusatory Instruction

Statement Writing

Debrief 


\section{Results}

Independent samples t-tests were conducted to determine the linguistic differences across guilty liars and innocent truth tellers. Three participants (all from the Liar condition were dropped from analysis for failing to comply with the experimental instructions (i.e. steal the flashdrive). Numbers in brackets represent the $95 \%$ confidence interval. Levine tests of homogeneity of variance were performed for each t-test. All tests failed to reach significance $(p s>.05)$.

\section{Total Words}

Liars used significantly fewer words in their statements $(M=150.94[110.78,191.10], S D$ $=80.76)$ compared to truth tellers $(M=253.92[190.80,317.04], S D=104.44) t(29)=$ $3.10, p=.004, d=1.15$.

\section{$1^{\text {st }}$ person pronouns}

First person absolute number. Marginal differences were observed in the absolute number of first person pronouns across liars and truth tellers, such that truth tellers used more first person pronouns $(M=20.46[13.91,27.01], S D=10.84)$ than liars $(M=14.39$ $[10.11,18.66], S D=8.60)$. Truth tellers used significantly more first person plural pronouns compared to liars $(M=.28[-.05, .61], S D=.67)$. No significant differences were observed for first person singular pronouns across liars $(M=13.63, S D=8.51)$ and truth tellers $(M=19.46, S D=19.80), p=.10$ (see table 2 for details). 
First person rate combined. As hypothesized liars used a significantly higher proportion of $1^{\text {st }}$ person pronouns relative to their overall word usage $(M=.11[0.08, .14]$, $S D=.06)$ compared to truth tellers $(M=.07[.05, .09], S D=.03) t(30)=2.19, p=.04, d=$ 0.79 .

$1^{\text {st }}$ person rate singular. Liars used significantly higher proportions of first person singular pronouns $(M=.11[.08, .14], S D=.06)$ compared to truth tellers $(M=.07$ $[.05, .08], S D=.03), t(30)=2.11, p=.02, d=0.77$.

$1^{\text {St }}$ person rate plural. Significant differences were not observed for usage rates of first person plural pronouns for liars $(M=.002, S D=.004)$ and truth tellers $(M=.004$, $S D=.007) p=.14$ (see table 3 for details).

$3^{\text {rd }}$ person Pronouns

$3^{\text {rd }}$ person absolute number. Truth tellers used significantly more third person pronouns $(M=17.85[9.75,25.96], S D=13.40)$ compared to liars $(M=8.47[5.27$, 12.40], $S D=7.17) t(30)=2.574, p=.02, d=0.87$. This was largely accounted for by truth tellers' usage of third person singular pronouns $(M=17.23[9.36,25.11], S D=$ 13.03) compared to liars $(M=8.39[4.87,11.91], S D=7.07) t(30)=4.61, p=.02, d=$ 0.64 . No differences were observed for third person plural pronouns across liars $(M=.47$, $S D=.77)$ and truth tellers $(M=.62, S D=.77) p=.63$ (see table 2 for details).

$3^{\text {rd }}$ person rates. No significant differences were observed for the proportional usage of third person singular across liars $(M=.05, S D=.04)$ and truth tellers $(M=.06, S D$ $=.04) p=.22$ or plural for liars $(M=.002, S D=.004)$ and truth tellers $(M=.002, S D$ 
$=.002) p=.22$ (see table 3 for details).

Table 2

Absolute number of words in statements by lying condition in Study 2

\begin{tabular}{|c|c|c|c|c|c|}
\hline & \multicolumn{2}{|c|}{ Liars } & \multicolumn{2}{|c|}{ Truth-Tellers } & \multirow[b]{2}{*}{$p$} \\
\hline & $M$ & $S D$ & $M$ & $S D$ & \\
\hline $\begin{array}{l}\text { Total } \\
\text { Words }\end{array}$ & 150.94 & 80.75 & 253.92 & 104.45 & .004 \\
\hline \multicolumn{6}{|l|}{$\begin{array}{l}\text { First } \\
\text { Person }\end{array}$} \\
\hline Combined & 13.89 & 8.63 & 20.46 & 10.84 & .06 \\
\hline Singular & 13.63 & 8.51 & 19.46 & 10.80 & .10 \\
\hline Plural & .26 & .65 & 1.00 & 1.35 & .05 \\
\hline \multicolumn{6}{|l|}{$\begin{array}{l}\text { Third } \\
\text { Person }\end{array}$} \\
\hline Combined & 8.47 & 7.14 & 17.85 & 13.40 & .02 \\
\hline Singular & 8.00 & 7.08 & 17.23 & 13.03 & .02 \\
\hline Plural & .47 & .77 & .62 & .77 & .61 \\
\hline
\end{tabular}


Table 3

Relative proportion of pronouns in statements by lying condition in Study 2

\begin{tabular}{|c|c|c|c|c|c|}
\hline & & & Trı & lers & \\
\hline & $M$ & $S D$ & $M$ & $S D$ & $p$ \\
\hline $\begin{array}{l}\text { First } \\
\text { Person }\end{array}$ & & & & & \\
\hline Combined & .11 & .05 & .08 & .03 & .04 \\
\hline Singular & .11 & .06 & .07 & .03 & .02 \\
\hline Plural & .00 & .00 & .00 & .00 & .14 \\
\hline $\begin{array}{l}\text { Third } \\
\text { person }\end{array}$ & & & & & \\
\hline Combined & .05 & .04 & .06 & .04 & .22 \\
\hline Singular & .05 & .04 & .06 & .04 & .22 \\
\hline Plural & .00 & .00 & .00 & .00 & .87 \\
\hline
\end{tabular}

\section{Discriminant Analysis}

Discriminant analysis was performed on the proportional usage of first person singular pronouns (overall first person pronoun rate was not included since it was accounted for by the first person singular rate). Since the greater absolute usage of third person pronouns was likely accounted for by truth-tellers' overall greater use of words in general (i.e. the relative rates were non-significant) a discriminant analysis was not performed on the third person total or third person singular pronoun totals. The analysis with first person singular pronouns yielded a significant discriminant function, $\chi^{2}(1, n=30)=4.07$, 
$p=.04($ Wilks' Lambda $=.87)$. Sixty percent of cases were correctly classified with $52.6 \%$ of liars and $70.0 \%$ of truth tellers being correctly classified.

The findings of Studies 1 and 2, although encouraging, were necessarily limited for several reasons. First, the inability to detect differences in third person pronouns in Study 2 potentially weakens the argument for the informativeness hypothesis for truthtellers. However, it is possible that use of third person pronouns was not natural since the participants were the only actors present in the laboratory during the critical portion of the experiment. Another limitation was present in the basic experimental design of Studies 1 and 2. Each experiment involved instructing participants to lie and to tell the truth. In the real world police cannot instruct suspects to lie or tell the truth. Suspects will spontaneously lie or truth tell of their own volition. The methodology of Studies 1 and 2 did not reflect that important real world factor. Finally, in Studies 1 and 2, participants were given little to no motivation to lie convincingly. The stakes facing liars in the real world as well as their motivation to lie convincingly can be extremely high. Study 3 attempted to address each of these concerns by adapting the Russano et al. (2005) cheating paradigm to be used in place of a traditional deception detection paradigm. The cheating paradigm allows participants to be implicated in an actual guilty action, and puts participants in a situation where most would lie in order to escape potentially severe academic dishonesty charges thus allowing spontaneous and uninstructed lying. The addition of a confederate in Study 3 may also aid in replicating the third person pronoun findings of Study 1 by providing truth tellers another actor to describe. 


\section{STUDY 3}

\section{Method}

Participants

Forty-one psychology undergraduate students were recruited from the Florida International University subject pool for extra credit. Participants were informed during recruitment that they would be taking part in a memory and intelligence experiment. Six participants were dropped from analysis, 3 because they expressed suspicion about the true purpose of the experiment, 2 who refused to cheat when prompted by the confederate, and 1 who (in the innocent truth teller condition) instigated cheating on their own. Participants identified as primarily Hispanic (51.5\%), with smaller proportions of those identifying as Caucasian (15.2\%), and as African American (24.2\%). Participants' ages ranged from $19-52$ with a mean age of 24.9. The sample consisted of mostly females (69.7\%). As in Study 2, participants self-reported English as their first language. Participants who considered English a second language were not permitted to sign up for the experiment via Florida International University’s electronic participant system.

\section{Materials}

Two scales were developed for the study. The first was titled the "Bloomfield Fluid Intelligence Test” and was taken directly from Russano et al.'s, (2005) original cheating paradigm study. The test included four problems divided into two separate packets. The first packet was labeled clearly as "Individual Questions" and the second packet was labeled clearly as Team Questions. The second scale was titled the 
Bloomfield Crystallized Intelligence Test. This scale included multiple choice questions taken directly from the logical reasoning section of a practice LSAT test. See Appendices F and G for scale details.

\section{Procedure}

Participants were assigned randomly into either a Guilty Liar or an Innocent Truth-teller condition, using an experimental paradigm based on Russano et al. (2005). Each participant was paired with one of four possible confederates (two males and two females). Upon arriving, participants were instructed by the experimenter that the experiment was not ready and asked participants to wait outside the lab with the confederate. The participant and confederate engaged in a brief rapport-building phase lasting approximately five minutes while they waited for the experimenter. After five minutes had passed the experimenter opened the lab and escorted both the participant and confederate inside. After providing written consent the experimenter explained that the participant would be engaging in a series of intelligence tests and that the purpose of the study was to compare shared versus individual intelligence. The testing room was windowless, small and bare, containing only a long table with two chairs situated across from each other.

Participants were instructed that it was very important that they follow the rules of the experiment, and keep in mind that cheating would be considered a violation of the University's academic dishonesty policy, which would result in serious consequences. Additionally, participants were informed that there were two distinct sets of questions: 
individual and team. Participants were told that they should always work on their own and not share answers or cooperate in any way on the individual problems. However they were expected to cooperate and should work together with the confederate on the team questions. Participants were instructed that they should alternate starting with a team problem, then moving to an individual problem, then moving back to a team problem and finishing with an individual problem. The experimenter set a timer for 15 minutes and left the room.

The experiment proceeded identically for liars and truth tellers with one critical difference. In the Guilty Liar condition, the confederate asked participants for help in solving the second individual problem (counting the number of triangles in the figure). In the Innocent Truth teller condition, the confederate did not ask participants for an answer on the individual questions, thus allowing the participant to independently complete all individual problems. After the first testing phase, the experimenter returned and informed the participants that time was up. The experimenter provided the second test instructing participants to complete it individually within 15 minutes. Participants were then reminded of the consequences for cheating and then were left in the room with the confederate while the experimenter reportedly scored the results from the first test. After approximately 5 minutes the experimenter returned and informed participants in all conditions that there was a problem with the first test. Specifically, both tests had the same answer for the triangle problem which was unlikely given that it was a trick question and it is highly improbable to generate the same response from two participants unless they shared answers. The experimenter then stated that this was potentially a very 
serious violation of the University's academic dishonesty policy and could potentially result in formal charges. However, since the experimenter was reportedly not sure of how to handle the situation s/he informed participants that he would need to call his/her professor for guidance. After leaving the room the confederate would in all cases state that the experimenter had no evidence of the participant and confederate actually cheating. In the guilty liar condition the confederate stated that he/she would not implicate the participant.

The experimenter returned and informed the participant that after calling his/her professor that there was indeed a potential problem, and that both the participant and confederate would need to be separated and asked about what happened for the official record. Participants were left alone in the test room while the confederate was escorted out. After approximately 5 minutes the experimenter returned alone and informed participants that because cheating was suspected a written and signed statement would need to be recorded. The experimenter also provided the same non-guilt-presumptive solicitation as in Study 2, that he/she personally did not suspect the participant had anything to do with the cheating, but that it was needed that the participant be honest and say what happened in as much detail as possible so that the relevant authorities (i.e. the professor and academic integrity officials) can get to the bottom of the situation. The experimenter also stated that while he/she could not be certain, if no cheating or sharing of answers was reported then it was unlikely that there would be any future consequences. Participants were provided with a notepad and a pen and then asked to write out their free recall statements of everything they remembered happening beginning 
with their arrival in the lab. Once participants completed their statements they were thoroughly debriefed as to the true nature of the experiment and dismissed with full credit for participating. As in Study 2, all liar statements were verified by the author as being actually lies (i.e. deceptive statements about not being involved in cheating when in fact cheating had occurred). Similarly, all truth teller statements were verified as being honest accounts of their experience in the lab during the experiment where no cheating occurred.

Coding. As with Studies 1 and 2 an automated script coded all participant statements exactly as described in both prior experiments. 
Figure 2

Diagram of Study 3 Procedure

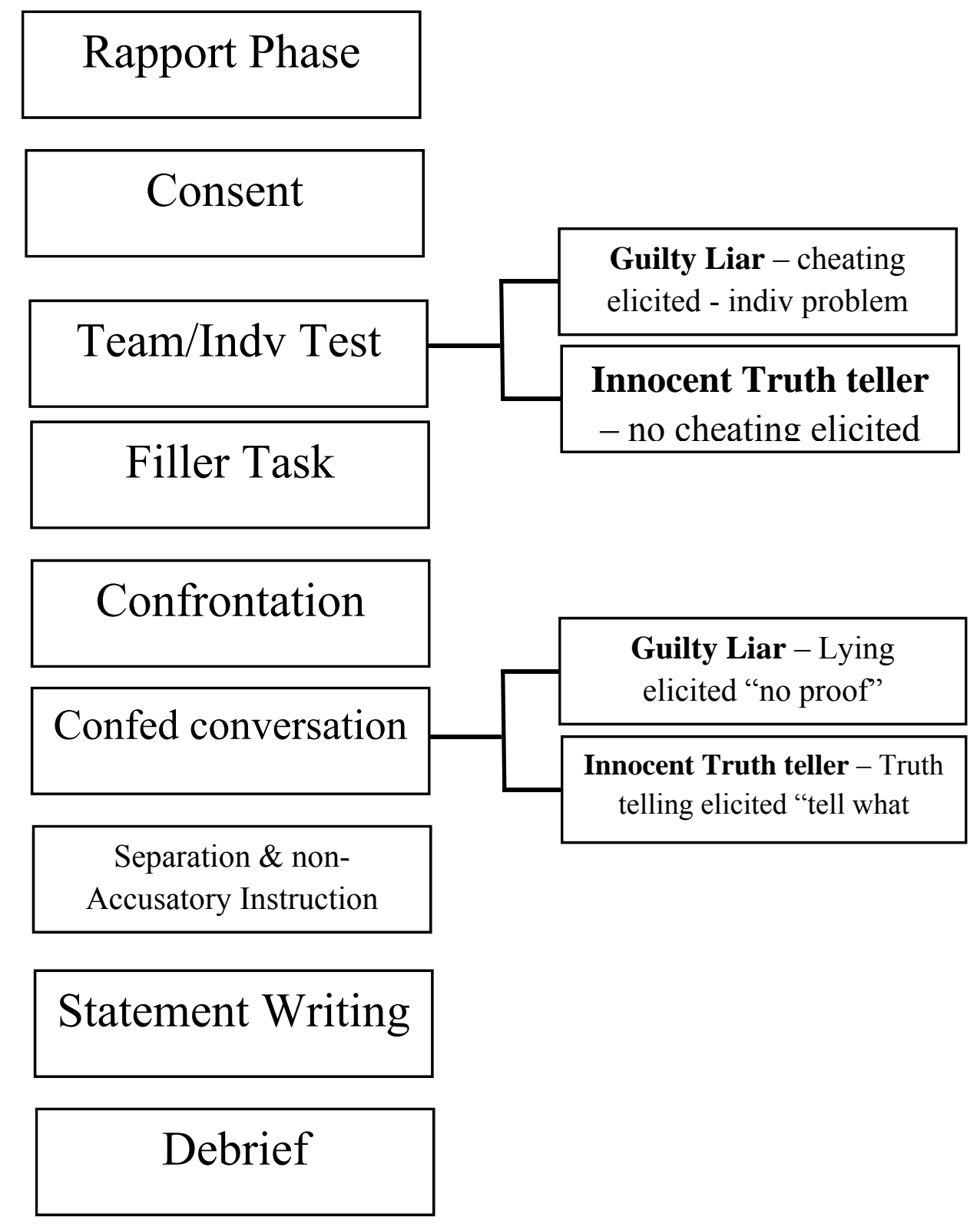




\section{Results}

Liars and truth tellers were compared using independent samples t-tests in four key ways:

First the total number of words, second, the raw numbers of first and third person pronouns, third the relative number of first and third person pronouns used over total words elicited, fourth the relative frequency (again to the total number of words used) of singular and plural first and third person pronouns. Levine tests of homogeneity of variance were performed for each t-test in the current experiment. Unless otherwise stated all homogeneity tests were non-significant $(p s>.05)$,

\section{Total words}

A Levine's test of variance homogeneity for total number of words used by liars and truth tellers, was significant. Under the assumption that equal variances were not assumed, an independent samples t-test was performed. Liars were found to be marginally less forthcoming in their statements than truth tellers, using fewer words in their statements $(M=141.44, S D=51.09,[114.21,168.67])$ than truth tellers $(M$ $=194.21, S D=102.33,[144.89,243.53]) ; t(33)=2.00, p=.06, d=0.35$.

\section{Absolute numbers of first \& third person pronouns}

The differences were not significant for the absolute numbers of first and third person pronouns (see Table 4 for details). 
Table 4

Absolute number of words in statements by lying condition in Study 3

\begin{tabular}{lcccccc}
\hline & \multicolumn{2}{c}{ Liars } & \multicolumn{2}{c}{ Truth-Tellers } & \\
& $M$ & $S D$ & $M$ & $S D$ & $p$ & \\
$\begin{array}{l}\text { Total } \\
\text { Words }\end{array}$ & 141.44 & 51.09 & 194.21 & 102.33 & .06 & Proportion \\
& & & & & al \\
First & & & & & frequency \\
$\begin{array}{l}\text { Person } \\
\text { Combined }\end{array}$ & 15.81 & 6.18 & 19.16 & 12.05 & .32 & offirst and \\
Singular & 8.44 & 3.33 & 9.47 & 8.93 & .66 & third \\
\multicolumn{1}{c}{ Plural } & 7.31 & 5.19 & 9.68 & 6.64 & .25 & person \\
& & & & & & pronouns
\end{tabular}

Third

Person

$\begin{array}{rrrrrrr}\text { Combined } & 4.18 & 4.35 & 7.42 & 7.28 & .19 & \text { The } \\ \text { Singular } & 3.73 & 4.47 & 6.74 & 6.49 & .19 & \text { overall } \\ \text { Plural } & .45 & .52 & .68 & 1.06 & .51 & \text { proportion }\end{array}$

of first person pronouns was, as predicted, significantly greater for liars $(M=0.12, S D=$ $0.03,[0.10,0.13])$ than for truth tellers $(M=0.09, S D=0.02,[0.08,0.11]) ; t(33)=2.12$, $p=.04, d=0.70$. We were unable, however, to detect differences in the proportion of third person pronoun usage $p>.05$ (see table 5).

Proportional frequency of singular and plural pronouns

The proportional singular pronoun usage was significantly greater in liars' statements $(M$ $=0.07, S D=0.03,[0.05,0.09])$ compared to truth tellers' statements $(M=.04, S D=0.03$, 
$[0.03,0.06]) ; t(33)=2.01, p=.05, d=0.81$. The proportion of singular first person pronouns accounted for the overall differences in proportional first person pronoun use as the proportion number of plural first person pronouns did not differ across liars and truth tellers $p>.05$. Significant differences were not observed for singular or plural third person pronouns across liars and truth tellers, $p \mathrm{~s}>.05$ (see table 5 for details).

Table 5

Relative proportion of pronouns in statements by lying condition in Study 3

\begin{tabular}{rccccc}
\hline & \multicolumn{2}{c}{ Liars } & \multicolumn{2}{c}{ Truth-Tellers } \\
& $M$ & $S D$ & $M$ & $S D$ & $p$ \\
\cline { 2 - 6 } First Person & & & & & \\
Combined & .12 & .03 & .09 & .02 & .04 \\
Singular & .07 & .03 & .04 & .02 & .05 \\
Plural & .05 & .04 & .05 & .03 & .84 \\
& & & & & \\
Third & & & & & \\
Person & & & .04 & .03 & .29 \\
Combined & .03 & .02 & .04 & .02 & .26 \\
Singular & .02 & .02 & .03 & .00 & .90 \\
Plural & .00 & .00 & .01 & & \\
\hline
\end{tabular}

Discriminant Analysis

Similarly to Study 2, a discriminant analysis was performed on the proportional use of first person singular pronouns. The discriminant analysis with first person singular 
pronouns was significant, $\chi^{2}(1, \mathrm{n}=35)=4.15, p=.04($ Wilks' Lambda $=.88)$. The discriminant function correctly classified $63 \%$ of all cases, with $56.3 \%$ of liars and $68.4 \%$ of truth tellers being correctly classified. 


\section{DISCUSSION}

The focus of the current dissertation was to examine a novel approach to deception detection via linguistic analysis of written statements. This approach was guided by the theory that liars and truth-tellers make use of differing strategies which will be reflected in their word use when asked to write statements about their experiences. Liars were theorized to be motivated primarily toward self-exoneration, and therefore their statements were thought to primarily focus on exculpating themselves. Truth-tellers motivated by an informativeness goal were hypothesized to write statements containing detailed observation focused information to investigators. I hypothesized that whereas guilty liars make exclusive use of an exoneration strategy, both informativeness and exoneration focused strategies may underlie the statements of truth tellers. In general if potential suspects were interviewed like cooperative witnesses those who were innocent should adopt an informativeness strategy whereas those who were guilty would invariably be focused on their exoneration. Treating witnesses and suspects nonaccusatorially would create observable differences in how their statements were written. Specifically, due to liars' focus on exoneration, I hypothesized that their statements would contain more self-reference exemplified by their increased use of first person pronouns compared to truth tellers. Similarly truth-tellers' statements, because of their informativeness focus, were expected to make use of more third person pronouns compared to liars. This research, may yield an empirically validated, and easily implemented technique for statement analysis. 
In Study 1 the primary goal was to demonstrate the existence and use of the informativeness and exoneration strategies as well as show that differing pronoun use exemplified these strategies. Participants served as mock witnesses to a staged crime and then received one of two random sets of instructions: one where they were simply asked to write everything they remember about the crime event, and a second where they were also informed that investigators suspected their involvement in that crime. I predicted that those in the "suspect" instruction condition would use more first person pronouns and fewer third person pronouns compared to those in the "witness" condition. The first and third person pronoun hypotheses were confirmed providing initial evidence that these strategies do exist and that they produced the hypothesized verbal differences. The data from this study highlight the sensitivity of witnesses to investigator suspicion and underlie the importance of how a cooperative witness is questioned, i.e. if witnesses are treated like guilty suspects their statements, even if non-implicating, may be less informative and indeed resemble the statements of guilty suspects. Importantly the data also gave reasonable cause to extend these hypotheses to liars and truth tellers in a controlled setting.

Study 2 sought to provide initial evidence that the pronoun use, based on differing verbal strategies, did in fact vary across liars and truth tellers. Participants were assigned randomly to either a guilty liar or innocent truth teller condition. In the guilty liar condition participants took part in a staged theft and were instructed explicitly to lie about their guilty action. All participants wrote out statements about what happened during the experiment and their word usage was analyzed. It was found that liars did in fact use 
proportionately more first person pronouns compared to truth tellers. Specifically, liars used more first person singular (e.g. "I") pronouns, while differences in usage rates of first person plural pronouns (e.g. "we") were not observed. This finding supports the hypothesis that liars were focused primarily on self-exoneration and that this strategy was indeed reflected in their pronoun use. Contrary to expectations, proportional differences in the use of third person pronouns (e.g. "he", "they") was not observed. There are several potential reasons for the different patterns of $1^{\text {st }}$ person and $3^{\text {rd }}$ person pronoun usage. First, the effect sizes for third person pronouns might be much smaller than for first person pronouns. A larger sample would then potentially show significant differences in third person pronoun usage rates. A second potential reason is that truthtellers were describing an event with primarily themselves as the actor in the experiment. Since there were no other people to describe-- other than the research assistant- truthteller statements may not have required using third person pronouns. A third potential reason might be that use of third person pronouns may not be indicative of an informativeness strategy, and that other linguistic differences may be better suited to exemplify this strategy. Obviously the conclusions of Study 2 need to be considered carefully, given the artificial nature of the lies in this experiment. More genuine, highstakes lying was needed to examine these verbal differences in a more ecologically valid environment such that the consequences for a guilty action being discovered were more severe, and the lies themselves were generated spontaneously from the guilty liar, not explicitly instructed by the researcher. 
Study 3 was in essence an ecologically valid replication of the findings of Study 2. In Study 3, a high-stakes (cheating) paradigm was used with the intention of making the environment more analogous to what suspects (both innocent and guilty) would encounter in the real world. Additionally, use of the high-stakes cheating paradigm allowed for an examination of genuine spontaneous lying in adult participants, which has not been widely adopted in the literature. Study 3 mirrored the findings of Study 2 , finding support for the first person pronoun hypothesis, although it failed to find differences in the use of third person pronouns. While non-significant, the means of third person pronouns were in the hypothesized directions, implying that perhaps with additional power a significant difference could have been observed across conditions. Importantly Study 3 replicated the findings of the previous two studies with participants' spontaneous lying. Liars made more self-reference exemplified by their use of first person singular pronouns, reaffirming the hypothesis that liars are more likely to make use of a linguistic strategy of exoneration compared to truth-tellers. Whereas truth tellers' use of an informativeness strategy is less clear, these studies together demonstrate an important difference between the statements of liars and truth-tellers, and may aid investigators to determine truthful from deceptive statements.

\section{Implications for Researchers and Practitioners}

The current dissertation challenges the prevalent theory regarding liars' use of first person pronouns. Although some linguistic theories of deception (e.g. Sapir, 2005) have not been validated empirically and are easier to discount, other linguistic theories (e.g. 
Neumann et al., 2003) have been scientifically validated. One possible reason for the difference between the findings in the current dissertation and the findings of Neumann et al., 2003, is a critically different mind-set between the liars of both studies. In each of the current studies, liars were told to conceal a guilty action, e.g. "I didn't steal the flashdrive. I was just working on my analogies test," or "I didn't cheat," "I didn't talk to the other participant at all.” In Neumann et al, liars took a stance that was directly opposed to what they actually supported, (e.g. an individual who was pro-choice in the abortion debate would be asked to write statements that were pro-life). The differences in the purpose or goal of these lies could account for a differing narrative structure. Since increased use of pronouns is hypothesized to be the result of a self-exoneration strategy, that particular strategic goal would not be present in a "devil's advocate" paradigm.

Another possible, related reason for the current dissertation's critical divergence from the linguistic analysis literature rests in the theory behind liars' use or disuse of first person pronouns. Whereas I argue that liars are motivated to write statements that are selfexonerating, Neumann et al., and Buller et al. (1994), argue that liars implicitly write statements that distance themselves from their lies. Given the differences in experimental paradigm, the goals of guilty liars in the current study are clearly very different from the goals of liars in Neumann et al.'s study. It may be the case when arguing for a stance one does not believe in that self-distance is the most frequently used strategy. Self-distancing as a linguistic strategy may be as the authors argue, exemplified by diminished use of first person pronouns. However, given a criminal context, when an individual is a suspect involved with a crime, self-exoneration may be a more fitting strategy for liars to 
use. It is reasonable and indeed data support the notion (Neumann et al., 2003) that when individuals wish, implicitly or otherwise, to distance their "persons" from their "statements" that fewer references to that first person or "self" would be made in their statements. In the current dissertation it was observed that individuals who were guilty and who lied about that guilt were more likely to self-reference. Rather than conflict with Neumann et al.'s prior work these data add an important qualification to their theory. The critical difference between both studies is the overarching goals the liars possessed. In the current study self-exoneration was the primary focus. In Neumann et al. the goal was in part to be convincing but also to dissociate their person from their statements. In order to satisfy a goal of self-exoneration the self must be referenced. Consider the following two statements: 1) "I had no part in the murder; I was with my friend at the bar," as opposed to 2) "There was a murder at the club, and many were present including some individuals at the bar". The self in statement 1 is the subject, the center, and the focus of the statement's narrative as shown by the writer's use of first person pronouns. Statement 2, however, does not even make clear if the statement writer was even involved in the events being described. Statement 2 adequately satisfies a dissociative goal but not an exonerative goal as it goes out of its way to avoid reference to the self. Depending on the goal of the statement writer the structure of a liar's statements should change. It may be the case that all liars share both exonerative and dissociative goals but when facing high stakes consequences, the exonerative goal becomes the primary focus of their statements. Both of these deceptive strategies and indeed the linguistic differences they produce may be exclusive to a specific typology of 
lying. This raises an important point that has not been adequately explored in the literature, that differing strategic goals may lead to differing linguistic differences. This would necessitate that investigators know what the hypothetical goal of a liar is before applying a particular linguistic detection method to analyzing a suspect's statements.

Another major contribution of the current dissertation to the deception detection literature is in its adaptation of an experimental paradigm that is ecologically valid and controllable in its production of spontaneous adult lying. Clearly the type of lie participants are driven to create has an important impact on their later statements, particularly given phenomena as complex as deception and as variable as individual language. Laboratory studies that do not successfully replicate the cognitive mind-set of guilty liars may require re-evaluation. The current paradigm (in Study 3 ) is also one of the few paradigms that allows for the examination of spontaneous lying in adults with minimal attrition. Many studies (e.g. Talwar \& Lee, 2002) have examined spontaneous lying with great success in children through the use of a hidden toy paradigm. Although adults are obviously less easily induced to commit a guilty action and subsequently lie about it, adapting the Russano et al. (2005) cheating paradigm to deception detection studies allows for spontaneous lying to be readily examined in adult populations. An adult spontaneous lying paradigm is important for a variety of reasons, firstly because it may allow for a more globalized theory of deception as a cognitive process.

Theoretically it could expand the fields' understanding how individual differences may contribute to one's ability to deceive. The developmental literature has made brilliant strides in examining how deception follows cognitive development, particularly with a 
child's theory of mind (Wellman, Cross, \& Watson, 2001). This paradigm may allow developmental researchers to examine deception across the cognitive lifespan. Critically expanded use of a cheating paradigm may lead to better understanding and the ability to predict good from poor liars.

The current dissertation also has some possible implications for law enforcement practitioners. An important distinction emerges between law enforcement and lay person's diagnostic ability to tell truthful from deceptive statements. Although law enforcement are not any better than laypersons at detecting lies, law enforcement are much more likely to err on the side of deciding that an innocent individual is lying (Bond \& DePaulo, 2006). Indeed, Meissner and Kassin (2002) found that North American law enforcement agents had a very clear guilt bias in their judgments of deceit. Although this did not affect their discrimination accuracy, given the findings of the current dissertation this particular law enforcement bias is problematic. In Study 1, all participants were innocent bystanders to a crime, yet some were informed that they were suspected of involvement. This impacted their statements where innocent truth-tellers potentially adopted a more defensive exoneration strategy, the same sort of strategy guilty liars may have taken in Studies 2 and 3. If a very mild guilt-presumptive instruction could induce innocent truth-tellers to produce statements that resemble guilty liars, more extreme forms of guilt-presumptive questioning (e.g. the Reid Technique; Inbau et al., 2013) could undermine legitimate attempts to detect deception.

Guilt presumptive questioning is inherently the result of investigator guilt bias, where investigators mistakenly assume that most of the individuals they interview are in 
fact guilty. Investigator guilt bias has numerous implications for proper law enforcement and in avoiding potential miscarriages of justice beyond the findings of the current dissertation. The false confession literature alone is replete with examples of how this particular confirmation bias can lead an innocent suspect to confessing to crimes he/she did not commit (see Kassin et al., 2006). But what about an otherwise cooperative witness? Fisher (1995) argues that due to law enforcement's natural link to the prosecution a guilt bias is a natural and expected consequence. A guilt bias would be more likely to yield "hits" or convictions if investigators have a lower criterion threshold for guilt (or indeed suspect all potential interviewees of being guilty). The obvious cost of this lowered criterion threshold for guilt as Fisher, Vrij (2008), and Kassin et al. (2006) argue, is that innocents will inevitably be falsely accused and potentially convicted. However given the results of the current dissertation there is a second and equally problematic implication of investigator guilt bias. Assuming an investigator is antagonistic, confrontational, or inquisitorial in his/her approach to witness interviewing, that investigator would assume the guilt of that investigator's interviewee with the primary goal of collecting incriminating evidence. Ironically, this sort of approach, given the results of Study 1, might be more likely to make innocent witnesses more likely to present themselves as guilty suspects, who naturally adopt a strategy of exoneration. If an investigator were to notice the "subject's" focus on self-exoneration and interpret that as a sign of guilt it could exacerbate the investigator's already present guilt bias. Even if the subject was eventually cleared of involvement, neither the investigator, considering the subject to be non-cooperative, nor the now antagonized witness would be likely to 
provide much in the way of additional information to an investigation. Inevitably this avoidable loss of a cooperative witness could hurt an investigation given the importance of cooperative witnesses in solving difficult cases (e.g. Riedel \& Jarvis, 1998; Wellford \& Cronin, 1999; Keel, Jarvis, \& Muirhead, 2008; Davis, Jensen, Burgette, \& Burnett, 2014). Investigator guilt bias clearly has a profound influence on innocent truth tellers, but its influence may also extend indirectly to guilty and deceptive individuals

Given the findings of the current dissertation avoiding investigator guilt bias is particularly important when using linguistic cues to deception. In a sense, truth-tellers may be more strategically flexible than liars, when producing statements. It seems reasonable then for investigators to assume cooperation and innocence when dealing with all potential suspects. Guilty liars, regardless of how they are questioned, should adopt an exoneration focused strategy whereas innocent truth-tellers can and do change their statements based on the context of the questions. Beyond the diagnostic value of innocence presumptive questioning, it could have an additional benefit of providing investigators with a cooperative witness. Considering the typical investigator guilt bias it may be the case that many otherwise cooperative witnesses are turned uncooperative undermining efforts to solve cases and serve justice to the community. Clearly, regardless of the technique or paradigm, the presumption of guilt matters and has a significant impact on the outcomes of cases. The results of the current dissertation suggest that erring on the side of innocence may better serve the accurate detection of deception. 
An important factor for adopting any technique in the law enforcement community is the ease with which it is implementable. Police officers receive surprisingly little training in how to detect deception. Bull (1989) surveyed 1,000 law enforcement agents and found that less than 10\% had received any deception detection training. Those who had received training reported that it consisted exclusively of simple cue-based techniques. Frank and Feeley (2003) affirm the importance of easy-to-learn deception-detection-techniques in their review of the current state of deception detection training. If easy-to-implement cue-based-techniques are currently being implemented by law enforcement then it stands to reason that ease of learning is critical to a technique's adoption. The obvious problem with many of the current easily learned and easily implementable techniques is that they are not in fact diagnostic of actual deception (DePaulo et al., 2003). The procedure proposed in the current dissertation satisfies both the concern of easy implementation and that of having empirical support. The differences in requisite training for a regularly used linguistic analysis technique like SCAN (Sapir, 2005) to the current the proposed technique are very apparent and illustrate a clear problem with SCAN's implementation. SCAN's most basic course consists of 26 hours over 3 days (retrieved February $21^{\text {st }}, 2015$ from http://www.lsiscan.com/scan_training.htm). The current technique would require no specialized training and could even potentially be automated by any software package that can parse words and calculate basic word-usage rates. The current technique could be a natural fit for the law enforcement community given its empirical support and its obvious learning advantages. 


\section{Future Directions}

There are a number of future directions for the current research into the hypothesized strategic and linguistic differences of liars and truth-tellers. Although the three studies in the current dissertation have demonstrated that differing strategic goals lead to diagnostic differences in the language of liars and truth-tellers, applying these differences as a deception detection technique should be expanded on and developed. Future research in this area could provide investigators with truthful and deceptive statements, and then examine the effects of instruction into pronoun differences on diagnostic ability. It may be particularly interesting to examine both trained and untrained statement analysts to examine how experience interacts with interpreting the pronoun instruction and subsequently influencing diagnosticity. A second relevant future direction for this research may be in spoken interviews/interrogations. Although the focus of the current dissertation has been on language use in written statements, the strategic goals should arguably be present regardless of whether an individual is speaking or writing out a statement for law enforcement. A future study in this vein would likely need to examine transcripts of recorded interviews. The interviews themselves would also likely need to be witness centric, encouraging them to speak for the majority of the interview and assuming innocence in all cases to elicit differences across liars and truth tellers. The current dissertation has examined a single possible linguistic cue that may be linked to liars' use of an exoneration strategy. The proposed third person pronoun strategy was not found to be linked to truth-tellers and an informativeness strategy. It may be beneficial to examine other linguistic and non-linguistic cues that are linked to 
liars' and truth-tellers' strategies. One possible approach would be to analyze units of meaningful information across liars and truth tellers. If truth-tellers are in fact using an informativeness strategy, their statements may then contain relatively more actual information compared to liars. Ultimately this research would need to apply to real world investigations. To that end future research should consider analyzing actual statements and/or interview transcripts to see if the verbal differences found in the laboratory with college students is generalizable to criminal populations. Finally given the success of the cheating paradigm at eliciting spontaneous lying in adults, future research should apply this paradigm to extend the field knowledge and theoretical understanding of deception as a cognitive process.

\section{Limitations}

Several key limitations are present in the current research. First and foremost is the issue of consequences. Real world consequences for guilty liars who have committed serious crimes are tremendously more severe than what participants faced in this study. Study 2 took on a more traditional approach in its deception paradigm and relied only on the consequence of having to write a lengthy essay which is hardly analogous to the real-world threat of incarceration. Study 3's use of a cheating paradigm with the consequence of expulsion from the University is likely as close as is both reasonable and ethical given the constraints of laboratory research. The fact remains, however, that criminals will always face graver consequences than can be replicated in the laboratory. Another key and related flaw in the current dissertation is the use of 
University students as participants. It is possible that the cognitive processes and deceptive strategies of young-adult college students are not analogous to those of realworld criminals. Future research would likely need to replicate the linguistic differences found in this dissertation within a more appropriate criminal population, either through field or laboratory testing. Although this research is certainly promising another potential flaw exists that may limit its applicability to liars in the real world. When truth tellers have not actually witnessed an event (e.g. they were home by themselves), their statements may not be analogous to an eyewitness operating on an informativeness strategy. A key potential flaw in the methodology of Studies 2 and 3 also potentially influence the generalizability of these results. Both studies were designed such that innocent truth tellers did not witness a crime. In the real world these truth tellers would be analogous to innocent alibi tellers. Since veracity is confounded in this experiment with the presence of a crime, these results may not generalize to innocent witnesses who did witness a crime. However given the findings of Study 1, where innocent truth tellers did observe a crime and similar patterns of pronoun use were observed, it is conceivable that the observed differences between liars and truth tellers would extend to innocent truth tellers who actually witness a crime. Future research however will need to more firmly establish this notion. Further research may be needed to elicit non-exoneration statements from innocent truth-tellers who have not witnessed anything relevant to an investigation. The current research also examined only fluent American English speakers. As a result these sensitive linguistic differences may be different for English speakers in other countries (e.g. the UK or Australia), as well as bilinguals who are not 
perfectly fluent in English. It is also impossible to extend the current results to other languages, and cultures where self-reference is perceived very differently (e.g. collectivist societies; Holtgraves, 1997). Finally, the current method of deception detection depends on witnesses cooperating to the extent that they will write out statements. If witnesses are unwilling to cooperate with law enforcement then the current deception detection method would not be usable. This may be particularly relevant in minority populations that have high levels of distrust of police (see Tyler, 2001).

\section{Conclusion}

The current dissertation proposed and tested two potential verbal strategies as well as the linguistic differences expected to result from them. Liars were hypothesized to self-reference more than truth-tellers because of their reliance on an exoneration strategy, whereas truth-tellers were expected to predominantly describe other objects/persons in their environment using an informativeness strategy. Self-reference was operationalized as using first person (particularly first person singular) pronouns, whereas informativeness was operationalized via the use of third person pronouns. Evidence was found first, that when exonerating oneself, self-reference was increased and exemplified via increased rate of first person singular pronouns. Second, liars were found to adopt an exoneration strategy automatically and used higher proportional rates

of first person pronouns. Unfortunately although some evidence was found linking use of third person pronouns to an exoneration strategy, truth-tellers were not found to use greater proportions of third person pronouns in their statements. As a technique for 
deception detection analysis of first person pronouns may be a simple and effective means of determining truthful from deceptive statements. Although this nascent approach requires considerable development before utilization in law enforcement it remains a promising approach that may be useful in investigative contexts saving time, training, and resources. 


\section{REFERENCES}

Aamodt, M., \& Mitchell, H. (2004). Who can best detect deception: A meta-analysis. [Presentation]. Rome: Annual meeting of the Society for Police and Criminal Psychology.

Akehurst, L., Bull, R., Vrij, A., \& Köhnken, G. (2004). The effects of training professional groups and lay persons to use criteria-based content analysis to detect deception. Applied Cognitive Psychology, 18(7), 877-891. doi: 10.1002/acp.1057

Blandon-Gitlin, I., Pezdek, K., Rogers, M., \& Brodie, L. (2005). Detecting Deception in Children: An Experimental Study of the Effect of Event Familiarity on CBCA Ratings. Law And Human Behavior, 29(2), 187-197. doi: 10.1007/s10979-0052417-8

Bond, C., \& DePaulo, B. (2008). Individual differences in judging deception: Accuracy and bias. Psychological Bulletin, 134(4), 477-492. doi: 10.1037/00332909.134.4.477

Bull, R. (2004). Training to detect deception from behavioural cues: attempts and problems. In P. Granhag \& L. Stromwall (Eds.), The detection of deception in forensic contexts (pp. 251-255). Cambridge: Cambridge University Press. doi: 10.1017/cbo9780511490071.011

Buller, D., Burgoon, J., Buslig, A., \& Roiger, J. (1994). Interpersonal Deception VIII: Further Analysis of Nonverbal and Verbal Correlates of Equivocation from the Bavelas et al. (1990) Research Journal of Language and Social Psychology, 13(4), 396-417. doi: 10.1177/0261927x94134003

Burgoon, J., \& Buller, D. (1996). Interpersonal Deception Theory. Communication Theory, 6(3), 311-328. doi: 10.1111/j.1468-2885.1996.tb00132.x

Caso, L., Gnisci, A., Vrij, A., \& Mann, S. (2005). Processes underlying deception: an empirical analysis of truth and lies when manipulating the stakes. Journal of Investigative Psychology and Offender Profiling, 2(3), 195-202. doi: 10.1002/jip.32

Colwell, L. (2006). The Training of Law Enforcement Officers in Detecting Deception: A Survey of Current Practices and Suggestions for Improving Accuracy. Police Quarterly, 9(3), 275-290. doi: 10.1177/1098611104273293

DePaulo, B., Lindsay, J., Malone, B., Muhlenbruck, L., Charlton, K., \& Cooper, H. (2003). Cues to deception. Psychological Bulletin, 129(1), 74-112. doi: 10.1037//0033-2909.129.1.74 
Hartwig, M., Granhag, P., Stromwall, L., \& Kronkvist, O. (2006). Strategic use of evidence during police interviews: When training to detect deception works. Law and Human Behavior, 30(5), 603-619. doi: 10.1007/s10979-006-9053-9

Hernandez-Fernaud, E., \& Alonso-Quecuty, M. (1997). The Cognitive Interview and Lie Detection: a New Magnifying Glass for Sherlock Holmes? Applied Cognitive Psychology, 11(1), 55-68. doi: 10.1002/(sici)1099-0720(199702)11:1<55::aid-acp423>3.0.co;2-g

Holtgraves, T. (1997). Styles of language use: Individual and cultural variability in conversational indirectness. Journal of Personality and Social Psychology, 73(3), 624-637. doi: 10.1037//0022-3514.73.3.624

Inbau, F. E., Reid, J. E., \& Buckley, J. P. \& Jayne, B. C. (2013). Criminal Interrogation and Confessions. Burlington, MA: Jones \& Bartlett Learning.

Johnson, M., \& Raye, C. (1981). Reality monitoring. Psychological Review, 88(1), 67-85. doi: $10.1037 / 0033-295 x .88 .1 .67$

Jones, E., \& Harris, V . (1967). The attribution of attitudes. Journal of Experimental Social Psychology, 3(1), 1-24. doi: 10.1016/0022-1031(67)90034-0

Kassin, S., \& Norwick, R. (2004). Why People Waive Their Miranda Rights: The Power of Innocence. Law and Human Behavior, 28(2), 211-221. doi: 10.1023/b:lahu.0000022323.74584.f5

Kassin, S., Drizin, S., Grisso, T., Gudjonsson, G., Leo, R., \& Redlich, A. (2010). Policeinduced confessions: Risk factors and recommendations. Law and Human Behavior, 34(1), 3-38. doi: 10.1007/s10979-009-9188-6

Kassin, S., Meissner, C., \& Norwick, R. (2005). "I'd Know a False Confession if I Saw One": A Comparative Study of College Students and Police Investigators. Law and Human Behavior, 29(2), 211-227. doi: 10.1007/s10979-005-2416-9

Kleider, H., Pezdek, K., Goldinger, S., \& Kirk, A. (2007). Schema-driven source misattribution errors: remembering the expected from a witnessed event. Applied Cognitive Psychology, 22(1), 1-20. doi: 10.1002/acp.1361

Mann, S., Vrij, A., \& Bull, R. (2004). Detecting True Lies: Police Officers' Ability to Detect Suspects' Lies. Journal of Applied Psychology, 89(1), 137-149. doi: 10.1037/0021-9010.89.1.137

Meissner, C., \& Kassin, S. (2002). "He's guilty!": Investigator bias in judgments of truth and deception. Law and Human Behavior, 26(5), 469-480. doi: 
10.1023/a:1020278620751

Nahari, G., Vrij, A., \& Fisher, R. (2011). Does the truth come out in the writing? SCAN as a lie detection tool. Law and Human Behavior. doi:10.1007/s10979-011-9264-6

Newman, M., Pennebaker, J., Berry, D., \& Richards, J. (2003). Lying Words: Predicting Deception from Linguistic Styles. Personality and Social Psychology Bulletin, 29(5), 665-675. doi: 10.1177/0146167203029005010

Pennebaker, J., Mehl, M., \& Niederhoffer, K. (2003). Psychological Aspects of Natural Language Use: Our Words, Our Selves. Annual Review of Psychology, 54(1), 547577. doi: 10.1146/annurev.psych.54.101601.145041

Porter, S., \& Yuille, J. (1996). The language of deceit: An investigation of the verbal clues to deception in the interrogation context. Law and Human Behavior, 20(4), 443-458. doi: 10.1007/bf01498980

Ruby, C., \& Brigham, J. (1997). The usefulness of the criteria-based content analysis technique in distinguishing between truthful and fabricated allegations: A critical review. Psychology, Public Policy, and Law, 3(4), 705-737. doi: 10.1037//10768971.3.4.705

Sapir, A. (1996). The LSI course on scientific content analysis (SCAN). Phoenix, AZ: Laboratory for Scientific Interrogation.

Sapir, A. (2005). The LSI course on scientific content analysis (SCAN). Phoenix, AZ: Laboratory for Scientific Interrogation

Smith, N. (2001). Reading between the lines: an evaluation of the scientific content analysis technique (SCAN). London: Home Office, Policing and Reducing Crime Unit, Research, Development and Statistics Directorate.

Sporer, S. (1997). The less travelled road to truth: verbal cues in deception detection in accounts of fabricated and self-experienced events. Applied Cognitive Psychology, 11(5), 373-397. doi: 10.1002/1099-0720(199710)11

Steller, M., \& Köhnken, G. (1989). Criteria Based Statement Analysis. In D. C. Raskin (Ed.), Psychological methods in criminal investigation and evidence (pp. 217-245). New York: Springer

Talwar, V., \& Lee, K. (2002). Development of lying to conceal a transgression: Children's control of expressive behaviour during verbal deception. International Journal of Behavioral Development, 26(5), 436-444. doi: 10.1080/01650250143000373

Tyler, T. R. (2001). Public trust and confidence in legal authorities: What do majority and 
minority group members want from the law and legal institutions?*. Behavioral Sciences \& the Law, 19(2), 215-235.

Tyler, T., \& Fagan, J. (2008). Legitimacy and Cooperation: Why Do People Help the Police Fight Crime in Their Communities?. Ohio State Journal of Criminal Law. 6 doi: $10.2139 /$ ssrn. 887737

Undeutsch, U. (Ed.) (1967). Beurteilung der glaubhaftigkeit von Aussagen. Handbuch der psychologie (Vol 11). Göttingen, Germany: Hogrefe.

Vrij, A. (2004). Why professionals fail to catch liars and how they can improve. Legal and Criminological Psychology, 9(2), 159-181. doi: 10.1348/1355325041719356

Vrij, A. (2005). Criteria-Based Content Analysis: A Qualitative Review of the First 37 Studies. Psychology, Public Policy, And Law, 11(1), 3-41. doi: 10.1037/1076-8971.11.1.3

Vrij, A. (2008). Detecting lies and deceit: Pitfalls and opportunities. ( $2^{\text {nd }}$ ed.) Chichester, England: John Wiley \& Sons. doi: 10.1515/9783110276794.321

Vrij, A., \& Mann, S. (2000). Telling and detecting lies in a high-stake situation: the case of a convicted murderer. Applied Cognitive Psychology, 15(2), 187-203. doi: $10.1002 / 1099-0720(200103 / 04) 15$

Vrij, A., \& Taylor, R. (2003). Police officers' and students' beliefs about telling and detecting trivial and serious lies. International Journal of Police Science \& Management, 5(1), 41-49. doi: 10.1350/ijps.5.1.41.11244

Vrij, A., Akehurst, L., Soukara, S., \& Bull, R. (2002). Will the truth come out? The effect of deception, age, status, coaching, and social skills on CBCA scores. Law and Human Behavior, 26(3), 261-283. doi: 10.1023/a:1015313120905

Vrij, A., Edward, K., \& Bull, R. (2001). Police officers' ability to detect deceit: The benefit of indirect deception detection measures. Legal and Criminological Psychology, 6(2), 185-196. doi: 10.1348/135532501168271

Vrij, A., Fisher, R., Mann, S., \& Leal, S. (2006). Detecting deception by manipulating cognitive load. Trends in Cognitive Sciences, 10(4), 141-142. doi: 10.1016/j.tics.2006.02.003

Vrij, A., Mann, S., \& Fisher, R. (2006). An Empirical Test of the Behaviour Analysis Interview. Law and Human Behavior, 30(3), 329-345. doi: 10.1007/s10979-0069014-3 
Vrij, A., Mann, S., Fisher, R., Leal, S., Milne, R., \& Bull, R. (2008). Increasing cognitive load to facilitate lie detection: The benefit of recalling an event in reverse order. Law and Human Behavior, 32(3), 253-265. doi: 10.1007/s10979-007-9103-y

Vrij, A., Mann, S., Leal, S., \& Fisher, R. (2010). "Look into my eyes": can an instruction to maintain eye contact facilitate lie detection?. Psychology, Crime and Law, 16(4), 327-348. doi: 10.1080/10683160902740633

Vrij, A., Semin, G., \& Bull, R. (1996). Insight Into Behavior Displayed During Deception. Human Communication Research, 22(4), 544-562. doi: 10.1111/j.14682958.1996.tb00378.x

Wechsler, D. (1997). Wechsler Adult Intelligence Scale (3rd ed.). San Antonio, TX: NCS Pearson. doi: 10.1002/9780470373699.speced2203

Zuckerman, M., Spiegel, N., DePaulo, B., \& Rosenthal, R. (1982). Nonverbal strategies for decoding deception. Journal of Nonverbal Behavior, 6(3), 171-187. doi: $10.1007 / \mathrm{bf00987066}$ 


\section{APPENDIX A}

\section{$\underline{\text { Study } 1 \text { Protocol }}$}

1. Experimenter hands out consent forms

2. Emphasize that "we have to keep on schedule", "Late participants won't be admitted", not "fair to all of you. Here I have your receipts for participation in the study that you can show your professors for class credit, They've all been signed and are ready for you to take once you complete the study. Credit will also appear on Sona but we've found participants like to also have a paper copy of their participation.

3. Introduce self: My name is Peter Molinaro I'm a $3^{\text {rd }}$ year graduate student at FIU in the legal psychology PhD program. I got my Undergraduate degree from Rutgers University in NJ. I'm studying how symmetry affects memory for faces in a group context.

Prior research has shown that symmetric patterns are better remembered than asymmetric patterns. What isn't known yet is how this relates to both faces and potentially the phenomenon of memory conformity. Memory conformity is when the retrieval of co-witnesses influences how events are remembered. Whether the same is true for facial memory is what we're trying to figure out here today. This is obviously important from a theoretical perspective. It's also very important from an applied perspective. Specifically we're hoping that this research will aid police when they are assessing the memorability of a face for use in either a lineup or a showup.

What I am going to do is show you all a series of faces of varying degrees of symmetry, next I'm going to test you all together on your memory for those faces. Then we'll all go off into separate rooms and you will be tested on your memory individually. Other conditions will involve people remembering faces outside of a group context as a control 


\begin{abstract}
APPENDIX A
condition. We'll use whats called an old/new paradigm to test your memory for faces. That means that some of the faces you will see will be the same as the faces you saw in the beginning and others will be foils or new faces that were not originally shown. The idea here is to correctly remember which faces were shown in the beginning and which faces are new during the memory test. Now before we begin I want to just emphasize that -
\end{abstract}

"Is this the right room for the study?"

"Yes but we've already gotten started"

"I'm sorry I'm late but I had trouble finding the room"

"sorry but I can't give you credit for being in the study. The rules are very clear that lateness cannot be tollerated in this experiment since it will really interfere with the results of the study.

"You've got to be kidding me that's bullshit. I'm 5 minutes late, I rearange my whole schedule for this and you're telling me that I can't do this now?"

"That's what I'm telling you. Its not fair to these people who have shown up on time for you to come in late and still get one of these participation recipts."

-Argue for a bit-

“Ok, listen I'm sorry your upset I won't give you a penalty since you did show up but right now you're taking up time from this experiment and I'm going to have to ask you to leave."

"Fuck you, asshole"

-Student storms off 


\begin{abstract}
APPENDIX A
"alright sorry about that anyway lets get back to the study. I'm going to show you the facial stimuli on this computer. Please pay close attention and I'll be back in a few minutes once it's done."

Experimenter leaves and starts computer program. While program is running - Naughty late participant comes back into the room takes the pile of credit receipts and runs out. Experimenter comes back into the room and says:
\end{abstract}

"What you just witnesses was a staged crime. I need to file a report about what just happened. What I need you to all do is write down everything you remember happening from coming in here to right now in as much detail as possible to aid in the investigation.

"I need to file a report about what just happened. Unfortunately in cases like this the university police will consider everyone a suspect until demonstrated otherwise. What I need you to all do is write down everything you remember happening from coming in here to now in as much detail as possible to aid in the investigation." 


\section{APPENDIX B}

\section{Study 2 Protocol}

Please arrive 15 minutes prior to each session.

1. Unlock the door to the lab. The lockbox combination is: 1234\#. Please make sure that after locking/unlocking the key always goes right back in the lockbox. NEVER take the key with you.

2. Turn on computer using the following userid/password - labuser/labuser

3. Prepare Participant study materials: 1) instruction packets w/ sign-in sheets 2) consent forms, and 3) test sheets

4. Make sure the key is hidden behind the sign and the flash drive is in its proper place (keep in mind the cabinet does not actually lock, the key is merely for show)

5. Look at Sona to confirm the identities of the participants arriving. You will be running one participant at a time. If a participant is a no show give them a penalty, if they are late but think you can fit them in without running into another session you can run them (at your discretion). If they are late and you do not think that you will be able to fit them in assign them a no-show (no penalty) on Sona. Also know in advance what participant numbers each participant will be given (this will be important when we need to match participant conditions to the data)

6. When the participant arrives have them sit in the conference room. Gather all study materials in advance and attach them to your clipboard. Be sure to label them with the participant \#. Give the participant a consent form and a pen. Explain that they should read over the consent form and sign it at the bottom.

a. Say: "Thank you for participating in our study. My name is and I will be taking you through the study today. The first thing I need you to do is to please read and sign this consent document. This consent form basically explains that 
APPENDIX B

you will not be hurt during the experiment. It also explains that your identity will be confidential and your name will never be printed. Finally, if you feel uncomfortable at all during the study you can discontinue at any time without any penalty. Let me know when you have read and signed the consent for"

b. Put the consent form in the "Consent Form Box" in the grey cabinet.

7. The study will be conducted in the Conference room. Explain a bit about the study.

Say: "For this study you will be answering some questions and asked to do several cognitive tasks. We are interested in understanding how metacognition guides cognitive performance. What I need you to do now is take this envelope and follow the instructions inside. Do not let me know what the instructions say or it will ruin the experiment. Also inside the envelope will be a sign-in sheet that we will use to keep track of which condition you were assigned to. I need you to put in (predetermined participant \#) on the sheet inside. When you have finished reading the instructions place them, and the signup sheet back in the envelop and seal it."

8. Provide the participant with a randomly selected envelope (make sure that it is random e.g. shuffled and you do not know which condition the participant has been assigned to). Leave the room so that the participant can read the instructions and fill out the envelope (about 3 minutes).

9. After you return take the puzzle box from my office and provide them the first puzzle. Ensure that the pieces are setup behind the gray screen and they should be displayed red side up. Arrange the pieces as per the instructions on the box in my office across from the participant. 


\section{APPENDIX B}

Say: "Your first task will be to complete this puzzle. Try to make a complete shape out of these pieces as quickly as you can. Keep in mind there is only one correct shape for this puzzle."

a. Take out your phone/watch and start the timer after saying:

b. Say: "Begin now."

10. Allow the participant 3 minutes to complete the puzzle.

a. After 3 minutes say:

b. Say: "Times up. Let's move on to the next task."

c. If participants finish before the 3 minutes are up:

d. Say: "Ok, Let's move on to the next task."

11. Gather up the pieces and provide participants with the Analogies questionnaire.

a. Say: "You will have 10 minutes to complete the following questions. Please try to be as accurate as possible. I will be in my office if you need anything just knock. Feel free to use the restroom if needed."

12. Leave Participants in the Conference Room for 10 minutes. Be sure to close the door to my office while they take the survey.

13. After the time is up go back into the room and begin the working memory test.

Say: "We're going to begin a test of your working memory capacity. I am going to say some numbers to you, for example 3- 6. After I've finished saying them you should repeat back to me the numbers you remember in the order I said them so you would say ' $3-6$ '. We will start out with just 


\section{APPENDIX B}

a two digits and increase it gradually as we progress through the test. Do you have any questions? ....Ok, lets begin"

14. After completing the working memory test:

Say: "Ok, I'm going to score your test results and input your data into the computer. I need you to stay in here while I do that. I should be back in a few minutes."

15. Close the door, open the safebox - combination 1234\# then close it. Wait 5 minutes then return to the conference room

Say: "Could you come into my office, I need to talk to you in there."

Take them to my office and say,

Say: “Ok, I need you to listen carefully to what I'm about to tell

you. Apparently a safe-box was recently opened containing a flash drive with the answer keys to many psychology exams. I just checked the safebox since my professor needed some copies made and it's not there. I definitely know it was there just before we started. Right now I really need your help. Anything you can remember will be really helpful in figuring out what happened. If you wouldn't mind I'd really appreciate it if you could type out in as much detail as possible everything that you remember about the session, beginning with your arrival at the lab, up until now. Please provide as much detail as possible, as the information you provide could be critical to us attempting to locate the missing flash drive. Even if you don't think it's important (for example a sound you heard, or a person you saw walk through here) it might help us catch who is responsible. Take as much time as you need. And thank you so much for your help with this I really appreciate it."

16. Stay in the room (but give them space) with participants, and allow them as much time as they need to compete this part of the study.

17. Once participants are finished typing: 


\section{APPENDIX B}

Say: "Ok, thanks for that. I really appreciate your help. I want to get some feedback from you before I tell you about the study fully. Ok so the experiment is over now - Let me tell you a bit about what the whole point of it was.

Some people were assigned to be criminals and were instructed to steal the flash drive out of the safe, while others were instructed to be innocent bystanders.

So now if you were the criminal I need you to tell me now and give me back the flash drive - don't worry you won't have to write an essay and you of course won't be in any trouble."

If they are the criminal say:

"Don't worry You didn't do anything wrong and were just following the instructions. Thanks for your help with this."

I want to start asking you a few questions,

First, let me just ask how you felt writing that statement?

What thoughts were going through your head?

Did you have anything in particular strategically in mind as you wrote it?

Did you feel guilty or like you were on the defensive? 


\section{APPENDIX B}

How motivated were you to help out in the investigation?"

18. Once the participants Finishes answering feedback questions:

Say: "Thanks. So, the true purpose of this experiment was to examine how individuals report statements to law enforcement. We predicted that individuals who were suspects were more focused on exonerating themselves and thus provided more self-referencing statements than individuals who were innocent. We also expected that participants who were innocent were motivated to be helpful and informative writing out fewer self-referenced statements.

If they were not the criminal move on with the script:

Now it's critical that no one else know about this experiment or it will completely ruin our future results. Now, I'm sorry to be a pain but I need you right now to look me in the eyes and say word for word 'I promise not to reveal anything about this study to anyone else,"'. [if they don't say this word for word e.g. they say 'I promise' or 'ok]' say: "Sorry to be a pain but I need you to say it word for word as I said it." [If they aren't looking in your eyes] say: "I'm sorry to be a pain but I need you to look me in my eyes while you tell me."

Answer any remaining questions then dismiss the participant

19. Remember to administer Sona credit, Ensure that the word documents with participant statements are saved as "pXX.doc" in the test folder in c: drive, where $\mathrm{XX}=$ participant \#. 


\section{APPENDIX B}

20. Before the next participant comes in make sure the flashdrive is back in place and study materials that may have been out are all back in their proper places. If a participant arrives early for the next session ask them to wait outside until you are ready for them (feel free to provide them with a chair from the conference room to sit outside with)

21. At the end of the day, put all materials away in my office and ensure the lab is locked before you leave. 


\section{APPENDIX C \\ Study 2: Guilty Liar Instructions}

You are going to play the part of a criminal in this study. Don't reveal to anyone your identity as the criminal until after the experiment is completely over. If you are not convincing in your role you will be asked to write a brief 5 page assignment. In order to be successful you will need to follow these instructions closely. The experimenter will not be able to answer any questions and you should not reveal your role or it will invalidate the results of the experiment. Your job will be to steal the answer keys to several psychology exams contained on a flash drive. The flash drive is located in a gray lockbox located on top of the filing cabinet directly across from you. The combination to this lockbox is 1234\#. The flash drive in question is black and red. You NEED to take it and keep it hidden.

At some point during the experiment, the experimenter will leave you alone in the room. The best time for this will be during the "analogies test" where the experimenter will leave you alone for 10 minutes. Feel free to just guess anything on this test - the results don't matter. What is important is that you use this time to steal the flash drive from the cabinet. Try to be as quiet as possible and take the flash drive. Again you MUST steal the flash drive and NOT get caught. DO NOT admit your guilt under any circumstance and at any point during the experiment. Keep in mind that at some point during the experiment it is possible the missing drive will be noticed and you will be asked about it. Until the experimenter tells you "the experiment is over" you should not reveal this information even if you are asked about it directly. You can and should lie if questioned.

When you are finished reading this put this paper back in the envelop and be sure to put down the number given to you by the experimenter on the included sign-in sheet as well as the current date and time. Please keep in mind the experimenter cannot and will not answer any questions about the information you just read on this paper. 


\section{APPENDIX D}

\section{Study 2: Innocent Truth-teller Instructions}

The current experiment tests a variety of cognitive functions surrounding working memory. Working memory is the system that actively holds multiple pieces of transitory information in the mind, where they can be manipulated. This involves execution of verbal and nonverbal tasks - such as reasoning and comprehension — and makes them available for further information-processing. Working memory is generally used synonymously with short term memory, depending on how these two forms of memory are defined. Working memory includes subsystems that store and manipulate visual images or verbal information, as well as a central executive that coordinates the subsystems. It includes visual representation of the possible moves, and awareness of the flow of information into and out of memory, all stored for a limited amount of time. Working memory tasks require monitoring (i.e., manipulation of information or behaviors) as part of completing goal-directed actions in the setting of interfering processes and distractions. The cognitive processes needed to achieve this include the executive and attention control of short-term memory, which permit interim integration, processing, disposal, and retrieval of information. These processes are sensitive to age: working memory is associated with cognitive development, and research shows that its capacity tends to decline with old age. Working memory is a theoretical concept central both to cognitive psychology and neuroscience. In addition, neurological studies demonstrate a link between working memory and learning and attention.

Theories exist both regarding the theoretical structure of working memory and the role of specific parts of the brain involved in working memory. Research identifies the frontal cortex, parietal cortex, anterior cingulate, and parts of the basal ganglia as crucial. The neural basis of working memory has been derived from lesion experiments in animals and functional imaging upon humans.

When you are finished reading this put this paper back in the envelop and be sure to put down the number given to you by the experimenter on the included sign-in sheet as well as the current date and time. Please keep in mind the experimenter cannot and will not answer any questions about the information you just read on this paper. 


\section{APPENDIX E}

\section{Study 3 Protocol}

Please read this script carefully and adhere to the steps below. This script will guide your interaction with the participant and confederate. You must recite verbatim the quoted sentences and paragraphs assigned to your role.

1. RA: Wait for a text from the confederate. Once the confederate texts you saying the participant set a timer for 5 minutes. **important participant cannot be more than 15 minutes late to the study or you will not have enough time to run them. You should consider the session canceled if the participant arrives more than 15 minutes late.** After the 5 minutes are up go out side the lab and say, "Hello, my name is - Are you here for the cognitive strategies study? Great! I'm an undergraduate RA working with Dr. Fisher on the project follow me and we'll get you started." Escort them to the "testing room" (lab conference room). Confirm that the participant is here the one scheduled for the study (be sure to ask the confederate as well) and remind them to turn their phones off as you walk to the lab. Ask the participant and confederate to have a seat. Next, have them sign in on the participant log by filling in their time of arrival and panther ID number on the log forms.

2. Confederate (C): Determine which condition you will be running before the participant arrives randomly (there are free coin flipping apps available on the appstore and android market). Do not let the RA know which condition the participant is in however be sure to record it somewhere (e.g. in your phone) and confer with the RA once the participant is done so that proper coding for the participant is recorded. You will wait at one of the seats outside the lab trying to engage in rapport building with the participant. Common topics of conversation that typically get participants chatting include classes, the studies they've already done, psychology/their major, what they do for work etc. Feel free to improvise. The critical element of rapport building is finding common ground with the participant. As as soon as the 


\section{APPENDIX E}

participant arrives text the RA letting him/her know. They will then set a 5 minute timer allowing for 5 minutes of rapport building. Follow the RA when prompted.

3. RA: Next, ask the confederate to have a seat, to provide you with proper identification, and to sign in on the participant log. Then say:

Okay, thanks (confederate's name) and (participant's name) for participating. I will now proceed to explain the "purpose of the study."

RA: "This study is about how people use cognitive skills to problem solve. We are interested in finding out whether people with certain characteristics are better problem-solvers and have more general knowledge. What I'm going to ask you to do today is solve many logic problems and answer a bunch of general knowledge questions. So before we get started, I will briefly go over this consent form with you and have you sign it if you agree to participate. Please feel free to read it over before you sign. ”

4. RA: Hand out the consent forms to both the participant and the confederate and go over the purpose of the study, compensations, and rules of privacy and confidentiality. As soon as they sign the forms, collect them and ask if they have any questions. If the participant has questions --answer them.

5. RA: Next, you will administer a total of two sets of questionnaires. The first set will be the revised version of the Bloomfield Fluid Intelligence scale. Then, for the second set, you will administer the revised version of the Bloomfield Crystalized Intelligence scale. 
6.

\section{APPENDIX E}

7. RA: For the first set, proceed to take the revised version of the Bloomfield Fluid Intelligence scale only from your clipboard and explain how to complete it by saying:

8. "What I have here is the Bloomfield Fluid intelligence scale. Here is the procedure that I want you to follow. Now there are two packets here. The first one here point to individual packet is the Team questions packet. For these questions the two of you must work together to complete the questions. The second packet here is the individual questions packet. For this packet you should complete the questions on your own. Remember - please do not talk to one another or share answers on these questions and please do NOT put your name or panther ID on any of your tests, because that violates our rules of confidentiality and could be a violation of the university honor code. You should start with the first question in the team packet then switch to the individual packet then go back and forth alternating until you have answered every question. You will have 15 minutes to complete both packets. Some of the problems are challenging, but please give it your best effort. This same procedure will apply to the second test, which you will get after you complete this first one. Any Questions? wait for questions. Ok, let's get started! I'll be keeping track of time while I work on some things in another room. I'll let you know when the time is up.

9. RA: Set up the alarm and as soon as you are done say: “Ok! Start now! Good luck!” Leave and close the door behind you. Wait until the alarm sounds before returning 


\section{APPENDIX E}

10. C: While filling out the questionnaire, you should appear to be struggling with coming up with some answers and even make some verbal expressions (e.g. ugh, OMG, "this is

so hard."). Always be friendly and make small talk regardless of condition throughout taking the test. On the team questions make sure you don't come up with the answer too quickly, have fun with it and try to be engaged but struggling.

a. In Liar condition - confederate should ask the participant what they got the 2 nd individual problem (the triangle problem), if participant is reluctant try to again emphasizing that it's not a big deal. After the second attempt stop trying. (Put an * next to the triangle question of your test which will signal to the experimenter to end the experiment prematurely)

b. In Truther condition - confederate should simply take the entire test working together on the team questions and independently on the individual questions and NOT make any request to cheat and try to not engage the participant at all in conversation.

11. RA: Once the alarm goes off, exit the room and go back to "the testing room" (205). Collect the questionnaires and put them on your clipboard. Then, take the Bloomfield Crystallized Intelligence scale (from your clipboard) and hand it out as you say: 


\section{APPENDIX E}

“Okay times up. Now I am going to ask you to follow the same rules when you take this next questionnaire. To summarize, answer every question on your own and don't write down your name or panther ID so we don't break our confidentiality rules. Remember not to discuss any answers with one another as that could ruin the results of our experiment and may result in charges of academic dishonesty. You will have 15 minutes to answer as many questions as you can. Now, I am going to set up the alarm for you." Set the alarm and say: "Start now!" Again close the door and exit the room behind you.

12. RA: Wait another 3 minutes, exit my office and go back to "the testing room." Open the door and say adamantly:

"Alright guys, it looks like we have a BIG problem here! Just so you know the authors of these tests include some trick questions. People don't ever know the answer to the trick questions. The issue here is that on the individual questionnaire you both got exactly the same answer on the triangle problem, now that's very very unlikely UNLESS you guys shared answers. This is really bad because it compromises the results of our entire study and is completely against the University's code of conduct. I need to go call my Professor who is in charge of this study, and he is NOT going to be happy about this. Just so you know my professor takes this stuff very seriously and it could end up leading to formal academic dishonesty charges with the dean. Leave the room and shut the door. Wait 2 minutes before re-entering 


\section{APPENDIX E}

13. C: Liar condition - make sure the the participant is aware that they are involved in a guilty action but get them to agree to cover it up - something to the effect of you're not going to rat them out if they agree to cover it up as well.

Truther condition - make sure the participant is aware that they did nothing wrong and to just tell the RA the truth and that you'll do the same.

14. RA: RA returns to the room. “Okay, I just talked to my professor. It looks like we DO have a problem. I need to talk to you both separately to get to the bottom of what happened. If you wouldn't mind coming to the other room with me [confederate name]. I'll be right back [participant name]. Return after 2 minutes.

15. RA: “Ok, I spoke [confederate name]. Now listen very carefully here and let me be perfectly honest with you. (deep sigh) We have no proof that anyone cheated. All the evidence is circumstantial. So I'm pretty certain if there is no cheating reported in either of your statements nothing will happen. I'm pretty sure that if any cheating happened you didn't have anything to do with it. Based on what I saw, I got really worried that someone didn't follow the rules of the experiment. As I said before its very likely that cheating did take place. This incident breaks the rules of the experiment, compromises the integrity of the study, and may actually violate the university's honor code concerning cheating. My professor wants you both to write out and sign statements describing everything that happened during the experiment since now we're going to have to file a report with the university and the IRB. Anything you can remember will be really helpful in figuring out what happened. If you wouldn't mind I'd really appreciate it if you could write out in as 


\begin{abstract}
APPENDIX E
much detail as possible everything that you remember about the session, beginning with your arrival at the lab, up until now. Take as much time as you need. And thank you so much for your help with this I really appreciate it. Anyway if you have any questions I can try to answer them, I'm just an RA though keep in mind and this hasn't ever happened before.” After questions “Ok, I'll check on [confederate name] to see how s/he is doing. I'll be back in a bit once you're done with your statement.
\end{abstract}

After participant finishes writing their statement. Begin debriefing with participant. Remember to record $\mathrm{P} \#$ for participant on their statement, Be sure to administer their Sona credit, and that you've recorded the proper information in the participant log (on google drive). 


\section{APPENDIX F}

Study 3: Cheating "Test"

Appointment Number:

BCIT ID number:

Authentication Code:

\section{BLOOMFIELD FLUID INTELLIGENCE SCALE}

\section{Individual Problem \#1}

Suppose you are a bus driver. On the first stop you pick up 6 men and 2 women. At the second stop 2 men leave and 1 woman boards the bus. At the third stop 1 man leaves and 2 women enter the bus. At the fourth stop 3 men get on and 3 women get off. At the fifth stop, 2 men get off, 3 men get on, 1 woman gets off, and 2 women get on. How many men are left on the bus, how many women are left on the bus, and what is the bus driver's name?

How many men are left on the bus?

How many women are left on the bus?

What is the bus driver's name? 


\section{APPENDIX F}

\section{Individual Problem \#2}

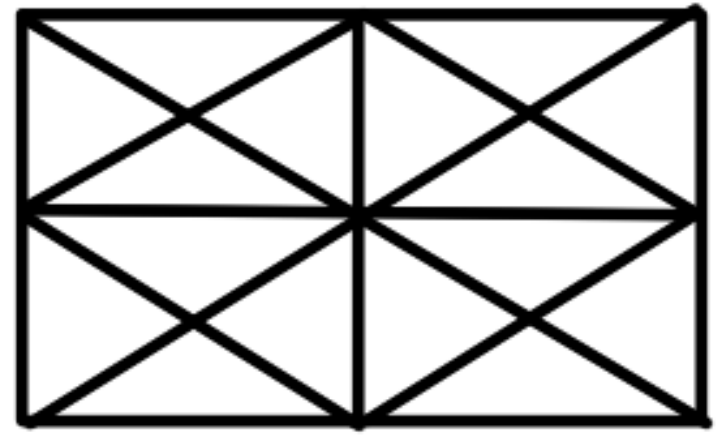

How many triangles can you find in the figure above? Look carefully - there are more than 16 !

Answer: 


\begin{abstract}
APPENDIX F
Team Problem \#1 Starting with the word "COOL", change one letter at a time until you have the word "HEAT". Each change must result in a proper word, and you can use any letters in the alphabet. Keep in mind that you can only change one letter per step, what is the minimum number of steps required to achieve this change? What are the steps?
\end{abstract}

Answer (Give Steps, i.e., the words): 


\section{APPENDIX F}

\section{Team Problem \# 2}

Right now Behtnay is 12 . You can find her older brother's age by switching the digits in Bethany's age. They'll be able to switch the digits in their ages again sometime in the future. How old will bethany and her brother be when this happens?

How old will Bethany be?

How old will Bethany's brother be? 


\section{APPENDIX G}

\section{Study 3: Filler "Test" \\ SECTION I \\ Time-15 minutes \\ 17 Questions}

Directions: Each group of questions in this section is based on a set of conditions. In answering some of the questions, it may be useful to draw a rough diagram. Choose the response that most accurately and completely answers each question and circle the corresponding item on your answer sheet.

\section{Questions 1-5}

A company employee generates a series of five-digit product codes in accordance with the following rules:

The codes use the digits $0,1,2,3$, and 4 , and no others.

Each digit occurs exactly once in any code.

The second digit has a value exactly twice that of the first digit.

The value of the third digit is less than the value of the fifth digit.

1. If the last digit of an acceptable product code is 1 , it must be true that the
(A) first digit is 2
(B) second digit is 0
(C) third digit is 3
(D) fourth digit is 4
(E) fourth digit is 0

2. Which one of the following must be true about any acceptable product code?

(A) The digit 1 appears in some position before the digit 2.

(B) The digit 1 appears in some position before the digit 3 .

(C) The digit 2 appears in some position before the digit 3 .

(D) The digit 3 appears in some position before the digit 0 .

(E) The digit 4 appears in some position before the digit 3.

3. If the third digit of an acceptable product code is not 0 , which one of the following must be true?

(A) The second digit of the product code is 2 .

(B) The third digit of the product code is 3 . 


\section{APPENDIX G}

(C) The fourth digit of the product code is 0 .

(D) The fifth digit of the product code is 3 .

(E) The fifth digit of the product code is 1 .

4. Any of the following pairs could be the third and fourth digits, respectively, of an acceptable product code, EXCEPT:
(A) $\quad 0,1$
(B) $\quad 0,3$
(C) $\quad 1,0$
(D) 3,0
(E) 3,4

5. Which one of the following must be true about any acceptable product code?

(A) There is exactly one digit between the digit 0 and the digit 1.

(B) There is exactly one digit between the digit 1 and the digit 2.

(C) There are at most two digits between the digit 1 and the digit 3.

(D) There are at most two digits between the digit 2 and the digit 3.

(E) There are at most two digits between the digit 2 and the digit 4.

Questions 6-10

Exactly three films - Greed, Harvest and Limelight — are shown during a film club's festival held on Thursday, Friday, and Saturday. Each film is shown at least once during the festival but never more than once on a given day. On each day at least one film is shown. Films are shown one at a time. The following conditions apply:

On Thursday Harvest is shown, and no film is shown after it on that day.

On Friday either Greed or Limelight, but not both, is shown, and no film is shown after it on that day.

On Saturday either Greed or Harvest, but not both, is shown, and no film is shown after it on that day. 


\section{APPENDIX G}

6. Which one of the following could be a complete and accurate description of the order in which the films are shown at the festival?
(A) Thursday: Limelight, then Harvest; Friday:
Limelight; Saturday: Harvest
(B) Thursday: Harvest; Friday: Greed, then
Limelight; Saturday: Limelight, then Greed
(C) Thursday: Harvest; Friday: Limelight;
Saturday: Limelight, then Greed
(D) Thursday: Greed, then Harvest, then
Limelight; Friday: Limelight; Saturday: Greed
(E) Thursday: Greed, then Harvest ; Friday:
Limelight, then Harvest; Saturday: Harvest

7. Which one of the following CANNOT be true?
(A) Harvest is the last film shown on each day of the festival.
(B) Limelight is shown on each day of the festival.
(C) Greed is shown second on each day of the festival.\$
(D) A different film is shown first on each day of the festival.
(E) A different film is shown last on each day of the festival

8. If Limelight is never shown again during the festival once Greed is shown, then which one of the following is the maximum number of film showings that could occur during the festival?
(A) three
(B) four
(C) five
(D) six
(E) seven

9. If Greed is shown exactly three times, Harvest is shown exactly twice, and Limelight is shown exactly once, then which one of the following must be true? 


\section{APPENDIX G}

(A) All three films are shown on Thursday.

(B) Exactly two films are shown on Saturday.

(C) Limelight and Harvest are both shown on

Thursday.

(D) Greed is the only film shown on Saturday.

(E) Harvest and Greed are both shown on Friday.

10. If Limelight is shown exactly three times, Harvest is shown exactly twice, and Greed is shown exactly once, then which one of the following is a complete and accurate list of the films that could be the first film shown on Thursday?
(A) Harvest
(B) Limelight
(C) Greed, Harvest
(D) Greed, Limelight
(E) Greed, Harvest, Limelight
Questions 11-17

A cruise line is scheduling seven week-long voyages for the ship Freedom. Each voyage will occur in exactly one of the first seven weeks of the season: weeks 1 through 7 . Each voyage will be to exactly one of four destinations:

Guadeloupe, Jamaica, Martinique, or Trinidad. Each destination will be scheduled for at least one of the weeks. The following conditions apply to

Freedom's schedule:

Jamaica will not be its destination in week 4 .

Trinidad will be its destination in week 7 .

Freedom will make exactly two voyages to

Martinique, and at least one voyage to

Guadeloupe will occur in some week between

those two voyages.

Guadeloupe will be its destination in the week preceding any voyage it makes to Jamaica.

No destination will be scheduled for consecutive weeks.

11. Which one of the following is an acceptable schedule of destinations for Freedom, in order from week 1 through week 7 ? 


\section{APPENDIX G}

(A) Guadeloupe, Jamaica, Martinique, Trinidad, Guadeloupe, Martinique, Trinidad

(B) Guadeloupe, Martinique, Trinidad, Martinique, Guadeloupe, Jamaica, Trinidad

(C) Jamaica, Martinique, Guadeloupe, Martinique,

Guadeloupe, Jamaica, Trinidad

(D) Martinique, Trinidad, Guadeloupe, Jamaica, Martinique, Guadeloupe, Trinidad

(E) Martinique, Trinidad, Guadeloupe, Trinidad, Guadeloupe, Jamaica, Martinique

12. Which one of the following CANNOT be true about Freedom's schedule of voyages?

(A) Freedom makes a voyage to Trinidad in week 6.

(B)Freedom makes a voyage to Martinique in week 5.

(C) Freedom makes a voyage to Jamaica in week 6.

(D)Freedom makes a voyage to Jamaica in week 3.

(E) Freedom makes a voyage to Guadeloupe in week 3.

13. If Freedom makes a voyage to Trinidad in week 5 , which one of the following could be true?
(A) Freedom makes a voyage to Trinidad in week 1.
(B) Freedom makes a voyage to Martinique inweek 2.
(C) Freedom makes a voyage to Guadeloupe inweek 3.
(D) Freedom makes a voyage to Martinique inweek 4.
(E) Freedom makes a voyage to Jamaica in week 6.

14. If Freedom makes a voyage to Guadeloupe in week 1and a voyage to Jamaica in week 5 , which one of the following must be true?

(A) Freedom makes a voyage to Jamaica in week 2.

(B) Freedom makes a voyage to Trinidad in week 2.

(C) Freedom makes a voyage to Martinique in week 3.

(D) Freedom makes a voyage to Guadeloupe in week 6. 


\section{APPENDIX G}

(E) Freedom makes a voyage to Martinique in week 6.

15. If Freedom makes a voyage to Guadeloupe in week 1 and to Trinidad in week 2 , which one of the following must be true?

(A) Freedom makes a voyage to Martinique in week 3 .

(B) Freedom makes a voyage to Martinique in week 4.

(C) Freedom makes a voyage to Martinique in week 5.

(D) Freedom makes a voyage to Guadeloupe in week 3 .

(E) Freedom makes a voyage to Guadeloupe in week 5 .

16. If Freedom makes a voyage to Martinique in week 3, which one of the following could be an accurate list of Freedom's destinations in week 4 and week 5, respectively?
(A) Guadeloupe, Trinidad
(B) Jamaica, Guadeloupe
(C) Martinique, Trinidad
(D) Trinidad, Jamaica
(E) Trinidad, Martinique

17. Which one of the following must be true about Freedom's schedule of voyages?

(A) Freedom makes a voyage to Guadeloupe either in week 1 or else in week 2.

(B) Freedom makes a voyage to Martinique either in week 2 or else in week 3.

(C) Freedom makes at most two voyages to

Guadeloupe.

(D) Freedom makes at most two voyages to Jamaica.

(E) Freedom makes at most two voyages to Trinidad.

STOP

IF YOU FINISH BEFORE TIME IS CALLED, YOU MAY CHECK YOUR WORK ON THIS SECTION ONLY.

DO NOT WORK ON ANY OTHER SECTION IN THE TEST 
APPENDIX H

$\underline{\text { Study 3: Debriefing Protocol }}$

\section{Instructions: Please read the following questions to the participant and record his/her responses fully in the space provided.}

1. Can you recall what the purpose of the study is?

2. Do you think we were tricking you or deceiving you in any way today? (record participant's response and then say the statement below)

Sometimes psychology researchers are not able to tell participants about the true purpose of an experiment, because it would affect the study's results. In fact, there was another purpose to today's experiment.

3. The person you witnessed cheating was not a 'real' participant, but an actor. On a scale from 1-10 $(1=$ not at all, $5=$ neutral, $10=$ extremely $)$

1. How believable was it that she/he was cheating? 


\section{APPENDIX H}

2. How believable was the claim that he/she was on academic probation?

3. How believable was the claim that there would be serious consequences for the person cheating (actor)?

4. How believable was the claim that there would NOT be serious consequences for you?

5. This experiment had nothing to do with Intelligence. Let me tell you a bit about what the whole point of it was. The student that was in the room with you before was actually a confederate working with us as part of the experiment. For some participants the confederate asked for help. The point of this was to implicate the participant in a guilty action and set it up so that participants would be predisposed to lie when asked to write out a statement to protect themselves from potential consequences. This was done to simulate a situation where people guilty of a wrong doing are questioned by authorities about a wrong doing and try to conceal it. For other participants the confederate didn't ask for help. This was done to simulate a situation in which innocent individuals might be questioned by authorities about an action they didn't commit. In this case it was cheating. Now I just want to emphasize that you were never in any trouble, in fact it can sometimes be considered commendable helping a peer who's struggling and is a pro-social action.

6.

Keep in mind that this experiment was designed so that nearly everyone who was in the guilty condition would lie. This is necessary since it is the focus of what we're interested in studying in this experiment. People lie all the time and while sometimes becoming aware of this is uncomfortable, keep in mind that your lying was both expected and necessary for the experiment to work. Let me just say again that you will not be in any trouble and were never going to be in trouble. I want to give you the opportunity to discuss any issues you had with the deception we used on you, give you the opportunity to voice any concerns and finally remind you of your rights to have your data destroyed and your participation in the study discontinued - if you decide to do this you will still receive full credit for participating. 


\section{APPENDIX H}

7. Say: "So, the true purpose of this experiment was to examine how individuals report statements to law enforcement. We predicted that individuals who were suspects were more focused on exonerating themselves and thus provided more self-referencing statements than individuals who were innocent. We also expected that participants who were innocent were motivated to be helpful and informative writing out fewer self-referenced statements. If you are currently experiencing any stress or psychological discomfort because of your participation in our study please let me know and I can provide you with a direct line to the University Counseling and Psychological services.

8. Do you have any questions?

9. How do you feel about your participation in this study?

Other than the true purpose of the experiment, did your experience differ in any way from what had been explained to you? If so, please explain.

10. It is very important for us to talk to you about CONFIDENTIALITY!! It is extremely important that other people don't find out what this study is truly about. If other people find out, then we won't be able to run this research anymore. It is critical that all participants come in here without any idea of what is about to happen in order to test our hypotheses accurately.

Furthermore, the results of this study may affect the lives of vulnerable individuals. For example, we will take these results and use them to train law enforcement on how to question children and adolescents and also mentally retarded individuals or those with mental illness who are great risk for false confession and spending time incarcerated for crimes that they have never committed. Therefore, it is imperative that you help us keep the procedures of this study confidential, so that we can make the most accurate recommendations 


\section{APPENDIX H}

possible to the legal and juvenile justice systems. Next, we would like for you to sign this 'Confidentiality Agreement' and sincerely appreciate your cooperation.

11. Please feel free to contact our primary investigator Peter Molinaro and Dr. Ronald Fisher should you have any questions or concerns. Further, if you feel the need to speak with a counselor as a result of this experience or any of your responses, you may contact the University Counseling Center at (305) 348- 2434. 
APPENDIX I

Demographics Form

Are you male or female?

Male

Female

What is your age?

What is your race/ethnicity?

Hispanic or Latino/a

Black or African American (non-Hispanic))

White or Caucasian American (non-Hispanic)

Native American or Aboriginal

Hawaiian or Pacific Islander

Asian or Asian American

Other: 
APPENDIX $\mathbf{J}$

$\underline{\text { Confidentiality Agreement }}$

\section{Name of Researcher: Peter Molinaro}

\section{Project Title: Cognitive Strategies}

\section{Participant Name:}

I, the undersigned, acknowledge, understand and agree to adhere to the following conditions.

Insert details of dataset fields and other information to be accessed in course of research

I will maintain the privacy and confidentiality of all information relating to my participation in the Cognitive Strategies study.

I will not disclose data or information to anyone other than those directly involved with the research project (Research assistants, Primary Investigator).

I acknowledge that I have been informed by a researcher about this agreement and the need for confidentiality regarding the Cognitive Strategies study.

I will not discuss the purpose goals or aims of this study with anyone outside of the research team until data collection is completed (January $1^{\text {st }} 2015$ ). 
APPENDIX J

Participant Signature:

X

Date: 
VITA

PETER F. MOLINARO

Department of Psychology

Florida International University

North Miami, FL 33181

\section{EDUCATION}

Florida International University Legal Psychology

Ph.D., 2015

(expected)

(Advisor: Ronald P. Fisher, Ph.D.)

Montclair State University Psychology

M.S., 2008

Thesis title: Are Jurors aware of Police Interrogative Tactics in Recorded Confessions? (Advisor: Jason J. Dickinson, Ph.D.)

Rutgers University

Psychology (Magna Cum Laude) B.A., 2006

\section{PUBLICATIONS AND PRESENTATIONS}

Fisher, R. P., Mosser, A., Molinaro, P. F., Satin, G. (In Press) Cognitive interview techniques. In A. Embar-Seddon \& A. D Pass (Eds.). Forensic Science. Pasadena, CA. Salem Press.

Molinaro, P. F. \& Fisher, R. P. Exoneration or Observation? Paper presented at Society of Applied Research in Memory and Cognition, Victoria, BC 2015

Molinaro, P. F., Charman, S. D., \& Wylie, B. K. Is the Relationship between preconfidece and accuracy as Tenuous as it Appears? Presented at meeting of American psychology Law Society San Diego, CA 2015 
Molinaro, P.F., Fisher, R. F., Mosser, A., Satin, G. (2015) Training the Trainer: A comparision of the Effectiveness of Law Enforcement Trainers instructed in Cognitive Interview Training Compared to those using typical witness interviewing procedures Paper presented at American Psychology Law Society meeting Sandiego, CA.

Malloy, L. C., Molinaro, P. F., Mungo, A. P., Rivard, J., (2014). Expert Opinion: Recantation in legal contexts. American Psychology-Law Society Quarterly

Molinaro P.F. \& Malloy, L. C. (2013) Statements from Youth in Legal Contexts: The Role of Age, Legal Role, and Consistency Paper presented at meeting of American Psychology Law Society, Portland, OR

Molinaro, P. F., Arndorfer, A., \& Charman S. D. (2013). Appearance-change instruction effects on eyewitness lineup identification accuracy are not moderated by amount of appearance change. Law \& Human Behavior. doi:10.1037/lhb0000049

Molinaro, P. F., Arndorfer, A., \& Charman, S. D. (2012) Are appearance-change Instruction Effects on Eyewitness Accuracy Moderated by Amount of Appearance Change? Paper presented at meeting of American Psychology Law Society, San Juan, PR

Molinaro, P. F., Dickinson, J.D., \& Wright, D. B. (2011) Are Jurors aware of Police Interrogative Tactics in Recorded Confessions? Paper presented at meeting of American Psychology Law Soceity, Miami, FL. 